\title{
Entre flor y flor (De unas propiedades de la palabra flor en la poesía de Góngora)
}

\section{NADINE LY \\ Universidad Michel de Montaigne, Burdeos}

Título: Entre flor y flor. (De unas propiedades de la palabra flor en la poesía de Góngora).
Title: Between Flower and Flower (about some Attributes of the Word for in the Góngora’s Poetry).

Resumen: Propone este artículo el análisis del uso semántico y semiótico que hace Góngora del significante flor(es) a lo largo de su producción poética. Se recalcan los juegos conceptistas y su neutralización, el sitio que ocupa la palabra en los textos, el sistema de rimas que rige, sus repeticiones y su papel relevante en la música de los poemas.

Palabras clave: España, Siglo XVII, poesía, Góngora, análisis semántico, análisis semiótico, retórica, ingenio, agudeza, conceptismo, "flor".

Fecha de recepción: 12/4/2013.

Fecha de aceptación: 1/6/2013.
Abstract: In this article the author develops a semantic and semiotic analysis of how Gongora uses the word "flor(es)" in his poetry. $\mathrm{He}$ emphasizes the conceptive play of words and their neutralization, as well as the importance of the word in the text, the system of rhymes it creates, its repetitions and its role in the musicality of the poems.

Key words: Spain, XVII century, poetry, Góngora, semantic analysis, semiotic analysis, rhetoric, "ingenio", play of words, conceptive use of words, "flor".

Date of Receipt: 12/4/2013.

Date of Approval: 1/6/2013. 
No brillan tantos astros en el firmamento, campean flores en el prado, cuantas se alternan sutilezas en una fecunda inteligencia.

\section{INTRODUCCIÓN: EL LÉXICO FLORIDO DE GÓNGORA}

Notable es la plasticidad referencial de la palabra flor que, ya desde el latín, se inscribe en tres campos semánticos, señalados por Ernout y Meillet ${ }^{1}$ : el primero, regido por la idea de que la flor es el elemento más hermoso de la planta, recoge cuantas expresiones definen, por medio de flor, la parte más fina, pura, excelente de metales, sal, harina, aceite, la élite de la juventud, de los poetas, de ciudades y países; el segundo, regido por la idea de que el momento en que florece es el mejor período de la vida de la planta, recoge cuantas fórmulas definen la flor de la edad, la primavera de la vida, la juventud, así como el estado óptimo de la fuerza física; y si se toma en consideración el olor, el tercero incluye la esencia de las flores y el "bouquet" del vino, por ejemplo. Además, el primer bozo se define como flor o flores de las mejillas y las figuras de estilo de la elocuencia o de la elocutio también son flores eloquentiae o verborum sententiarumque flores.

En 1605, al dirigirse al Lector de sus Flores de poetas ilustres de España, entre las que ocupan el primer lugar las "flores" gongorinas (38 poemas), escribe Pedro Espinosa ${ }^{2}:$ "[...] para sacar esta Flor de harina, he cernido dozientos cayzes de Poesía, que es la que ordinariamente corre [...]”. En su fundamental estudio de la antología ${ }^{3}$, señala Pablo Villar Amador antecedentes del título elegido por Espinosa:

1 Alfred Ernout et Antoine Meillet, Dictionnaire étymologique de la langue latine, Histoire des mots, Paris, Klincksieck, 2001, p. 241.

2 Texto facsímil de la edición de Valladolid, 1605, impresa por Luis Sánchez, digitalizada por la Universidad Complutense de Madrid, http://alfama.sim.ucm.es/ dioscorides/consulta_libro.asp?ref=B194381878idioma $=0$

3 Pablo Villar Amador, Estudio de las "Flores de Poetas ilustres de España" de Pedro Espinosa, Granada, Servicio de Publicaciones de la Universidad de Granada, 1994, pp. 55-56. 
Con respecto al título, conocida es la amplia tradición de diferentes autores que simbolizan en la flor el perfume lírico, a la vez breve e intenso, de toda composición poética. Autores como Octavio Mirandola (Illustrium poetarum flores per Octavianum Mirandulam collecti...; Antuerpiae, Ex Officina Ionnis Loëi, MDXLIV), Girolamo Ruscelli (I fiori delle rime de poeti illustri...; Venezia, G. Battista e Melchior Sessa fratelli, 1588) o el compilador de las célebres Flores de Baria Poesía (cancionero mexicano de 1577), componen diversos pétalos florales de esta tradición que tuvo presente Espinosa ${ }^{4}$.

Un ilustre antecedente medieval fue Pedro López de Ayala quien, en el prólogo de sus Morales sobre Job, comenta:

Son dichos flores por que asy como las flores en el arbol parescen bien y fazen al arbol mas fermoso, y son de muestra del fruto que llevara el arbol, ca dellas nasce el fruto, bien asy como estos dichos en este libro contenidos son en sy muy fermosos y fructosos, fazen al onbre, que es dicho en la escritura arbol, muy compuesto y fermoso y fructuoso en buenas obras delante Dios y delante los onbres y dan el olor de buena fama y fructo dulçe y muy sabroso y provechoso de obras meritorias.

Tanto en el campo de la botánica, como de la poesía y la escritura, la enseñanza moral y religiosa y la educación del hombre, anunciando la hermosura, el color y el olor de las flores el altísimo grado de perfección de sus frutos, le compete al significante flor abreviar, a modo de emblema verbal, la belleza del mundo y de los seres.

Sin embargo, bien es sabido que no hay símbolo que no presente dos caras opuestas y, en apariencia, contradictorias. En su Tesoro, apunta Covarrubias los numerosos casos en que se usa la palabra flor, concediendo unas líneas no escasas a la acepción pícara. Ocioso resultaría reproducir su artículo si, en el marco de esta reflexión más bien dedicada al significante que a sus variaciones semánticas, no importara oponer a la multiplicación de referencias y acepciones la singular unicidad del término:

4 En su nota 22, trae Pablo Villar Amador, op. cit., p. 56, otros "pétalos florales de esta tradición": "[...] el Cancionero llamado Flor de enamorados, de Juan de Linares (Barcelona, Bornat, 1562); la Flor de romances, glosas, canciones y villancicos (Zaragoza, 1578); la Floresta de varia poesía, de Diego Ramírez Pagán, etc.”. 
FLOR. [...]. Dizese de las yervas que echan flores, y especialmente de las olorosas. Los árboles echan su flor antes que el fruto y la mesma fruta, quando no está ahajada, dezimos está cogida con su flor. El lustre de cada cosa dezimos flor, por el resplandor que da de sí. En el cordován llamamos flor y grano lo adereçado y lustroso, y lo contrario llaman carnaza y envesado. Flor de la canela, lo muy perfeto. En el vino se llama flor una natilla que haze en lo alto de la cuba. Flor en la donzella, se dice la virginidad y entereza, que como flor que está asida a su mata o rama, está lustrosa, alegre y rutilante; en cortándola luego se marchita. De do se dixo desflorar, corromper la donzella y estragar alguna cosa lustrosa, manoseándola y sobajándola. En los metales llamamos flor una hoja muy delgada que despiden de sí, quando, sacándolos de la fragua, se caldean echándoles agua. Flor, entre farfantes burladores, llaman aquello que traen por ocasión y escusa, quando quieren sacarnos alguna cosa como dezir que son cavalleros pobres, o soldados que vienen perdidos, o que han salido de cautiverio, y desas flores son tantas las que ay en el mundo, que le tienen desflorado. La flor de la juventud, o adolescencia, dezimos aquella hermosura y lustre que muestra en sí la edad que empieça a florecer para dar fruto en la madura virilidad [...]. Juego de la flor, juego de tahures. La flor es simbolo de la brevedad de nuestra vida, que es como la florecita que sale a la mañana y se marchita a la puesta del sol [...]. Esparzir flores era ordinario en los sacrificios y en los regozijos y fiestas en las mesas de los combites [...] (El subrayado es mio).

Casi todos los referentes apuntados por Covarrubias se encuentran en la poesía de Góngora, como se podía esperar dentro de un marco cultural y erudito compartido por el poeta y por el lexicógrafo. Está bien representada la acepción retórica o erudita ${ }^{5}$, ausente del Tesoro, con no pocas innovaciones

5 En el famoso romance del autorretrato (1587), Hanme dicho, hermanas, los vv. 97-99 evocan, entre los bienes que posee el que hizo / a "Hermana Marica", un jardin de flores / y una muy gran silva / de varia lección, que recuerdan claramente el Jardín de flores curiosas de Antonio de Torquemada (1570) y la famosísima Silva de varia lección de Pero Mexía (1540). El no llevar mayúscula favorece la ambigüedad: como si crecieran en un jardín plantado de flores y en una silva/selva de varia lección, 'de varia lectura o interpretación', los árboles de las dos enciclopedias tienen hojas/ páginas que no solo son de leer, sino que también se usan en ocasiones menos intelectuales y, según comenta Carreira, más bien escatológicas (Luis de Góngora, 
escatológicas o jocosas, señaladas en el curso de este estudio. Recordemos que si el Diccionario de autoridades ${ }^{6}$ multiplica las entradas de Flor, el Léxico del marginalismo del Siglo de oro, de José Luis Alonso Hernández, ofrece nada menos que 28 entradas con flor o palabras derivadas, vinculadas todas con las nociones de trampa y engaño, juego de naipes, delincuencia, prostitución, designando por ejemplo el floreo "la abundancia de palabras en el orador, quando no aprietan y tan solo atienden a tener benéolos y atentos a los oyentes [...] (Covarrubias)", mientras que a la sola palabra flor le corresponden siete referencias: trampa de cualquier tipo, engaño o astucia, juego de naipes, lance en el juego de la perejila, individuo perjudicial, injuria escrita con intención crítica, virgo de la mujer ${ }^{8}$.

El léxico "florido" de Góngora abarca 16 palabras distintas con la siguiente repartición (salvo error mío): desflorar 2, flor (es) 132, Flor 1 (nombre), Flora 6, florecer 1, floreciente (s) 7, Flordelis 2, florentín 1, Flores 7 (el marqués Flores de Ávila), floresta 6, Floresta 1 (libro), florete 1, Florián 1, florido (a, os, as) 22, florín 1, Villaflor 2. Las palabras menos usadas, a veces son unos hápax, merecen una atención particular ya que pueden surgir señalando alguna que otra propiedad específica del significante flor. Otro cómputo, hecho a partir de la edición Millép, permite

Antología poética, ed. de Antonio Carreira, Col. Clásicos y modernos 30, Barcelona, Crítica, 2009, p. 140).

6 Ed. facsímil, Madrid, Gredos, 1969, vol. II: flor (16 acepciones y 17 fórmulas compuestas), floraina, flordelisar, flordelisado, florear (5 acepciones), floreado, florecer, floreciente, florecido, florecilla o florecita, florentissimo, floreo, florero (6 acepciones), floresta, florestero, floreta, floretada, florete (sustantivo), florete (adjetivo), floretear, floreteado, floridamente, floridissimo, floridito, florido (5 acepciones y 2 fórmulas), florifero, florígero, florín, floripondio, florlisado, florón, floroncos, Flos Sanctorum.

7 José Luis Alonso Hernández, Léxico del marginalismo del Siglo de Oro, Salamanca, Universidad, 1977: flor, arrugarse la flor, dar en la flor, juego de la flor, llevar la flor, flor birlesca, flor de aduana, flor de mercado, flor de virtudes, flor del cambio, flor encubierta, flor fresca, flor llana, floraina, florainero, florear, florear el garlo, florear el naipe, floreo, decir de floreo, floreo de Vilhán, florero, flores de cantueso, flores llanas, Florián, florida picardía, florido, florin, florino.

8 Alzieu, Jammes, Lissorgues, Poesía erótica del Siglo de Oro, con su vocabulario al cabo, por orden de a.b.c., Toulouse, Université de Toulouse-le-Mirail, France-Ibérie Recherche, 1975.

9 Luis de Góngora, Obras completas, Recopilación, prólogo y notas de Juan Millé y Giménez, Isabel Millé y Giménez, Madrid, Aguilar, 1956. 
apreciar el lugar ocupado en cada uno de los subgéneros poéticos por el lexema -flor-, aislado en forma de sustantivo o raíz y sílaba inserta en términos más complejos: 18 casos en poemas de arte mayor; 42 en letrillas y poemas de arte menor; 60 en romances; 34 en sonetos; 6 en la Fábula de Polifemo; 21 en Soledad primera; 7 en Soledad segunda; 6 en Panegírico al Duque de Lerma. En total, vemos y oímos unas 193 veces (salvo error mío) el elemento gráfico/sonoro -flor- cuando recorremos en su conjunto la poesía gongorina, quedando excluidos los numerosos nombres de flores que componen uno de sus paradigmas más importantes. Si contamos por año, a partir de la edición de Antonio Carreira ${ }^{10}$, observamos dos "épocas" distintas en la repartición de -flor-, menos importante en la primera, mucho más numerosa en la segunda. Entre 1581 y 1607, alcanza la representación del lexema un pico de 7 en 1582 y 1603; aparece 5 veces en 1584 y 1591; 4 veces en 1590 , 1602 y 1607; 3 en 1600 y 1605; 2 en 1585, 1589, 1593 y 1594 y una vez en los poemas de 1581, 1586-1588, 1596-1598 y 1606. Entre 1608 y 1626, época "florida" de la poesía gongorina, -flor-alcanza un pico de 22 casos en 1613; 14 en 1609, 1612 y 1621; se da 13 veces en 1614; 11 en 1608; 9 en 1620; 7 en 1617; 6 en 1622; 5 en 1610; 4 veces en 1611, 1619 y 1624; 3 en 1615 y 1618 y solo una vez en 1616 y 1625 . Tales resultados, cotejados con otras indicaciones cuantitativas, tal vez puedan contribuir a esbozar el desarrollo cronológico, genérico y léxico de la escritura gongorina.

No estudiaré, en estas páginas, el "tema” de las flores en la poesía de Góngora $^{11}$, ni el simbolismo de las flores ${ }^{12}$, sino el hiperónimo flor (o la

10 Luis de Góngora, Obras completas I, Poemas de autoría segura, Poemas de autenticidad probable, ed. de Antonio Carreira, Madrid, Fundación José Antonio de Castro, 2008². Salvo indicación distinta, las citas de Góngora remiten a esta edición.

11 Javier de la Peña Álvarez, Flores en la poesía española del Renacimiento y Barroco, , Madrid, Universidad Complutense, 2010, 766 pp., en una tesis reciente emprende el estudio de siete flores (rosa, clavel, lilio/azucena, jazmín, violeta, narciso y jacinto, junto con varias otras) en los textos poéticos de Garcilaso, Gutierre de Cetina, Francisco de la Torre, Herrera, Góngora, Quevedo y Francisco de Rioja.

12 Cf. el análisis que hace Antonio Carreira del poema-alegoría "Esperando están la rosa" en "La especificidad del lenguaje gongorino", Bulletin Hispanique, Langue, Littérature, Littéralité, coordonné par F. Bravo, CXII, 1 (2010), pp. 93-94: "Góngora tardó bastante en afrontar la alegoría, al menos la coextensiva al poema. 
sílaba -flor-) en cuanto elemento relevante del utillaje léxico-semántico y recurso semiótico usado por el poeta. Solo intentaré analizar los casos que me parezcan más espectaculares y significativos para ilustrar las propiedades del lexema. Considerando que -flor-era y sigue siendo un bien poético común y, más que común, casi vulgar, dos opciones eran posibles: por una parte, ejemplificar el tratamiento gongorino del tópico, encareciendo su plasticidad referencial (por ejemplo su especial ductilidad semántica, apta para juegos ingeniosos, dilogías, equívocos) y sus cualidades formales (por ejemplo su capacidad de imantar, en singular o en plural, un paradigma conocido de rimas); por otra, atendiendo a figuras retóricas sencillas pero eficaces (la repetición, por ejemplo), recalcar la calidad sonora y gráfica del significante también tratado por Góngora como "objeto” verbal, icono o emblema. Sin necesidad de atribuirle referencia ni fuente precisas, -flor-, evidente "alhaja" léxica, es capaz de iluminar cualquier contexto, lírico e idealizado o pícaro y groseramente escatológico, en el que esté inserta funcionando, no pocas veces, como motor de sugerentes paronimias y como nexo o cruce de complejas incitaciones interpretativas: ligadas al contexto y extraordinariamente enmarañadas, acaban esas, paradójicamente, por liberar al significante, invitando al lector a recrearse en el saboreo de su mero advenimiento.

\section{UN PERRILLO LLAMADO FLOR ${ }^{13}$}

Este poema, como "Casado el otro se halla" (n 194) y "Con Marfisa en la estacada” ( $\mathrm{n}^{\circ} 193$ ), es uno de los más atrevidos de Góngora, que

El romance «Esperando están la rosa», de 1609, es un tour de force en que la primavera se describe como si fuera un palacio: la rosa es la reina, las espinas son archas, el clavel es príncipe de la sangre, el jacinto inscribe un lamento en sus pétalos, el jazmín espira ámbar, el narciso abandona la fuente... Sigue el lilio, cortesano celoso, mosquetas y clavellinas son damas de la reina, las azucenas pasan por dueñas de honor, las violetas por meninas, un laurel sirve de jaula a unos ruiseñores, un ciprés hace de guardadamas, y los estanques de bufones. Era casi imposible mantener las correspondencias a lo largo de 96 versos. Para no forzar las cosas, Góngora permite que el jacinto, el jazmín y el narciso queden libres de equivalencia [...]” (p. 93).

13 A la hora de darse este volumen a la imprenta, se publicó un excelente artículo de Giulia Poggi, "Entre eros y botánica (la décima "Yace aquí Flor, un perrillo"), 
los escribió a una edad ya avanzada. La aspereza del tema sexual está en los tres casos elegantemente oculta por la alegoría $[\ldots]^{14}$.

Con esas palabras y unas pocas notas tan precisas como luminosas, comenta Antonio Carreira la décima de 1622: "De un perrillo que se le murió a una dama, estando ausente su marido”. Consiste aquí el velo alegórico en una agudeza nominal que pone en juego tanto el nombre del perrito, Flor, como el clavel que ha de crecer en la tierra que cubre su cuerpo y el sustantivo flor, última palabra del poema, y entre cuyos otros muchos hipónimos figura clavel. Siguiendo en el campo de la agudeza nominal botánica, establece la décima, en sus últimos dos versos, una doble correspondencia entra la hierba y la flor y los nombres de una hierba y de una flor forjados sobre lengua, buey y perro : "lengua de buey" y "lengua de perro"15. Carreira señala la existencia de una flor llamada "la lengua de perro o Cynoglossum of., que da flores rojas", si bien puntualiza que "Góngora se refiere al clavel de v. 5, lengua o signo del perro (= Flor) allí enterrado". La lectura de la décima muestra que, dentro de la agudeza nominal enmarcante, otra, también botánica, medicinal, erótica y fundada en ingeniosos equívocos y paronimias, señala claramente la atrevida alusión sexual de los primeros cuatro versos :

en Góngora y el epigrama. Estudios sobre las décimas, Juan Matas Caballero, José María Micó, Jesús Ponce Cárdenas (eds.), Universidad de Navarra-IberoamericanaVervuert, 2013, pp. 189-205, del que, desgraciadamente, no he podido beneficiarme. 14 Luis de Góngora, Antología poética, p. 629. Cf. también Antonio Carreira, "Defecto y exceso en la interpretación de Góngora”, Gongoremas, Barcelona, Península, 1998, pp. 47-73 y, para la décima, pp. 70-71.

15 Diccionario de Autoridades: LENGUA DE BUEY. Planta sylvestre, que crece en los campos. Tiene las hojas largas, ásperas y sutiles, algo roxas y armadas de agúdas espinas. Echa cantidad de talluelos, que como van subiendo, ván perdiendo de su grandeza, y entre las hojas de estos echa unas flores purpúreas, y en ellas una simiente semejante a una cabeza de víbora [...]. Es mui conocida por su valor esta planta, y llamase comunmente Buglossa sylvestris, que es léngua de buey salvage, por la grande aspereza que muestra en sus hojas.

LENGUA DE PERRO. Planta que se cria en lugáres arenosos, y se extiende sobre la tierra con unas hojas mas pequeñas que las del ancho llantén, y mas vellosas. Llamóse assi por que sus hojas tienen la figura de la lengua del perro [...]. 


\begin{abstract}
Yace aquí Flor, un perrillo que fue, en un catarro grave de ausencia, sin ser jarabe, lamedor de culantrillo: saldrá un clavel a decillo la primavera, que Amor, natural legislador, medicinal hace ley, si en hierba hay lengua de buey, que la haya de perro en flor.
\end{abstract}

Radica la cruda y conceptuosa alusión en el doble sentido de lamedor: "el jarabe que se da para que poco a poco el enfermo lo deje ir deslizándose por su garganta, y en esto difiere de la bebida" (Covarr.), aquí también sustantivo verbal de "lamer" (Carreira, loc. cit.) $)^{16}$, y en el doble nombre, etimológico y silenciado (capillus Veneris) y botánico vulgar (culantrillo) de la planta que tanto sirve para confeccionar el lamedor / jarabe, como para suscitar, al contacto con el derivado de lamer, una evidente paronomasia escabrosa. Es, en efecto, tan apretado el juego verbal que, como señala Carreira, "el jarabe de culantrillo se tomaba como pectoral", lo que remite al catarro grave del segundo verso. Ahora bien, para abarcar en su total obscenidad la primera redondilla de la décima, apreciando el valor impudente de catarro y de flor, conviene recordar con Autoridades:

CATARro. La fluxion ù destilacion que cae con excesso de la cabéza a las naríces, boca y pecho; aunque los Médicos extienden a mas partes del cuerpo esta destilacion de la cabeza, y la suelen dar otros nombres.

y con Corominas:

FLOR. [...] En el sentido de 'menstruación de la mujer' está ya en Nebr.; en bajo latín se documenta desde la primera mitad del siglo XIII [...]: es probable, por lo tanto (aunque no puede descartarse del todo la

16 Aut.: LAMEDOR. Composicion pectorál que se hace en las boticas, y tiene una consistencia media entre electuário y xarábe, y se dá a los enfermos para que poco a poco la dexen deslizar por la garganta al pecho. Pudo llamarse assi del verbo Lamer, porque este género de medicamentos se toman como lamiendolos [...]. 
vieja etimología fluor 'flujo') que se trate de un uso metafórico de flor, sea por el color de la sangre o porque el menstruo se comparó a la flor que precede al fruto o niño.

Asimismo, los últimos dos versos que, al cerrar la décima, ocupan el lugar de la salida ingeniosa - desempeño de la agudeza o, al contrario, como en este caso y otros muchos, clímax de la dificultad conceptuosa- concentran cuantas interpretaciones sugieren los versos anteriores. Estos (los primeros cuatro), en efecto, ofrecen una muestra poco común de deslices referenciales que, al favor de una que otra palabra, crean entornos semánticos tan prontos a manifestarse como a esfumarse, en cuanto sobreviene un vocablo que permite un nuevo juego a dos o más luces. El remanso semántico se produce, como era de esperar, en los dos versos de enlace (ac) de las dos redondillas (abba cddc): saldrá un clavel a decillo / la Primavera, que Amor, y se mantiene en los siguientes dos (cd): natural legislador / medicinal hace ley, reuniendo los tres campos -floral, erótico, fisiológico y medicinal- cuyo cruce ocasiona el juego de equívocos. Corresponde la elección del clavel al insistente carácter erótico de esta flor en la poesía gongorina y a su constante asociación con los labios ${ }^{17}$. La aparición del

17 Cf. Jesús Ponce Cárdenas, El tapiz narrativo del Polifemo: eros y elipsis, Barcelona, Universitat Pompeu Fabra, 2010, las páginas dedicadas a "La abeja y la flor: paradigma para un pequeño escorzo", cap. 2 ("Las horas no relatadas: función y alcance del silencio en el poema gongorino"), 2.2.3., pp. 94-111 y, en especial, a propósito de la octava 42: "Por supuesto, casi resulta una obviedad apreciar cómo la figuración de la boca de la ninfa -en tanto flor roja de suntuosos pétalos purpúreos- enlaza con una prolija serie de elaboraciones análogas que se remontarían, al menos, hasta 1582, pues ya en el celebérrimo soneto del carpe diem podía leerse: "mientras a cada labio por cogello / siguen más ojos que al clavel temprano". Desde aquella juvenil imitación de Bernardo Tasso, la sensual imagen aplicada a la belleza femenina no habría de apartarse de la escritura gongorina: "en dos labios dividido I se ríe un clavel rosado" (Hero y Leandro, 1610, vv. 137-138), "despacio rompía el capullo, / como temiendo salir / ante el clavel de sus labios, / dulcemente carmesí" (Las firmezas de Isabela, jornada III, vv. 2345-2349), "no para una abeja sola / sus hojas guarda el clavel" (romance Guarda corderos, zagala, 1621, vv. 25-26)... En definitiva, a la luz de esta gavilla de testimonios, no parece arriesgado afirmar que el espaldarazo gongorino al tópico de la boca-clavel debió de contribuir no poco al éxito de "una de las flores inevitables del Barroco»". La fórmula es de Álvaro Alonso, "El clavel como motivo poético", en AA. VV., I Canzonieri di Lucrezia, 
clavel, aunque no logra borrar las alusiones a las dos plantas de los vv. 9 y 10, la buglossa (lengua de buey) y la cinoglossa (lengua de perro), nos invita sin embargo a considerar con más atención la ley del amor médico que le otorga a una flor, el clavel, el poder de hablar representando al perro Flor: que la haya [lengua] de perro en flor. Pero nos incita también a añadir otra lectura, más directa, a las que preceden. En su última nota, señala Carreira, a propósito del verso 10: "Torrente Ballester ve en este verso igual sentido que en el v. 4 (La saga-fuga de J.B., p. 182)", con lo que volvemos a la atrevidísima sugerencia de esa lengua del perro Flor lamiendo una flor metafórica, sexual y/o relacionada con el menstruo. En su famosa conferencia sobre La imagen poética en don Luis de Góngora, encarece Federico García Lorca ${ }^{18}$ el "erotismo puesto en sus últimos términos" de la Fábula de Polifemo y Galatea y añade: "Se puede decir que tiene una sexualidad floral. Una sexualidad de estambre y pistilo en el emocionante vuelo del polen en la primavera". A pesar del aparente abismo que separa las dos composiciones, la percepción de la "sexualidad floral" en la décima tiene al menos una ventaja: la de modificar la interpretación del v. 9, si en hierba hay lengua de buey, haciendo que se entienda literalmente, ya que la lengua del buey, cuando está paciendo, lame la hierba. Asimismo modifica la interpretación global del poema que si bien es un acertado y agudo juego, atrevido, impudente y jocoso, no deja sin embargo de transfigurar la crudeza del tema sexual en logro estético por medio de la flor, literal y metafórica, que corona el diminuto edificio conceptista. Suavizando la insolente alusión y dando cima al poemita, se combina la función de calderón musical del término flor con el icónico adorno final, el floreo, que constituye, de por sí, el significante.

¿Qué conclusiones sacar de este examen de la décima en cuanto a las propiedades del significante flor? Primero, resalta la función estructurante que le atribuye la escritura gongorina, colocándolo en el primer verso y en el último del poema; segundo, su ya señalada,

Padova, Unipress, 2005, pp. 193-205 (p. 203). Cf. también Luis de Góngora, Fábula de Polifemo y Galatea, ed. de Jesús Ponce Cárdenas, Madrid, Cátedra, 2010, pp. 306-307.

18 Federico García Lorca, Obras completas, Madrid, Aguilar, 1960, p. 83. No podía menos Jesús Ponce Cárdenas de citar a Lorca en El tapiz narrativo del Polifemo, op. cit., pp. 110-111. 
notable pero controlada, labilidad referencial y su aptitud a emplearse, en equívocos y juegos conceptuosos, como nombre propio ${ }^{19}$ y común ; tercero, su función estética que, combinada con su doble situación clave en la décima, podría justificar un análisis más sintético o más "ascético" de los versos. En efecto, una lectura que no desembocara en una descripción detallada, atenta a la complejidad de los equívocos y juegos etimológicos, léxicos y semánticos, sino que respetara la brevedad y densidad del poemita, ¿en qué elementos se fijaría? Ciertamente, en la música floral que abre y cierra la décima: v. 1 Flor, un perrillo, v. 10 de perro en flor; luego en el verso 4: lamedor de culantrillo, el más grosero y cómico, pero al que sustituye inmediatamente un verso más "poético", delicado y enigmático. Con un verbo en futuro: saldrá un clavel a decillo, anunciador de la estación florida (la primavera del v. 6), de la resurrección y transformación post mortem del perrillo y de la palabra memoriosa de la flor, el quinto verso y el clavel marcan el cambio de tono y tenor, sugiriendo humorísticamente la metamorfosis, como la de tantos amantes mitológicos, del perrillo en clavel, cumpliéndose así, además, el destino que le reservaba su nombre, Flor. Los últimos dos versos, cierre estratégico de la décima, en que tiene que resolverse el "enigma" del verso 5, justifican la metamorfosis aportando pruebas no solo naturales y botánicas sino lingüísticas y eróticas. ¿De dónde procede la impresión de desempeño, de alivio y de suavidad que uno siente al leer los vv. 9 y 10? Tal vez de su fluidez, debida a las sinalefas (sien hierbhay - lhaya perroen) y de la articulación ambigua, semiconsonántica y semivocálica, de la yod (hierba hay buey haya); de

19 Remito otra vez al artículo de Antonio Carreira, "La especificidad del lenguaje gongorino", pp. 89-112. Comentando la letra de la letrilla Aprended, Flores, en mí, escribe a propósito de lo que él llama "refuerzo del significante" (p. 99): "Algo similar vemos en la cabeza de la célebre letrilla: "Aprended, Flores, en mí / lo que va de ayer a hoy" (1621). Las cinco mudanzas que comentan esta cuarteta, la más glosada de la literatura española, recorren la maravilla, el clavel, el jazmín, el alhelí y el girasol, desde la más efímera a la más duradera. Pero el estribillo apunta asimismo al Marqués de Flores de Ávila, quien había visitado al poeta cuando estaba enfermo. Aunque no se puede saber si Góngora hubiera escrito de todas maneras la letrilla en otras circunstancias, lo cierto es que, una vez leído el epígrafe, quien resulta aleccionado por la fugacidad de la maravilla no son solo las flores sino el marqués, de ahí que convenga editar Flores con mayúscula" (p. 100). 
la convocación de una "autoridad" natural: la lengua de buey en la hierba legitima la de perro en la flor, desatándose así las tensiones entre procacidad y alegoría encubridora; también y quizás más que todo se deba al verbo impersonal en subjuntivo, que la haya, que prolonga la perspectiva abierta por el futuro del v. 5, sugiriendo posibilidades y virtualidades entre las que culmina, como broche que cierra perfectamente la espiral del poemita, la magnífica fórmula final: que la haya de perro en flor, otorgándole al significante flor el privilegiado estatus de cifra preñada de referencias en cuanto "mot de la fin" del poema.

\section{La última palabra: Fabula de Polifemo $Y$ GALATEA, 35 CON OTROS VERSOS Y CASOS}

Sirve de remate la palabra flor, las más de las veces en plural, a varias estrofas internas y a algunos poemas (unos veinte casos en total), como cierre provisional o final, cada vez, de un movimiento ascendente o de un balanceo rítmico que culminan en el emblemático significante de la belleza natural, la poesía lírica, el amor como núcleo del lugar ameno. Cifra asimismo el significante del leniter dicere, opuesto al aspere dicere, el estilo robusto o áspero, la dicción blanda, suave y placentera encanta y seduce tanto por su música sonora como por la conveniencia que Lope atribuía a los tópicos. También satisface su vaporosa y vaga referencia general, paradójicamente asociada a un clarísimo paradigma de motivos y, según los tipos estróficos, de rimas consonantes. Un primer ejemplo: el final de un soneto remoto, de 1585 (Carreira, 51, p. 61), opone a la sangrienta pasión del amante la bellísima indiferencia floral de Clori:

A vista voy (tiñendo los alcores en roja sangre) de tu dulce vuelo, que el cielo pinta de cien mil colores,

tanto, que ya nos siguen los pastores por los extraños rastros que en el suelo dejamos, yo, de sangre, tú de flores. 
Mientras que puede parecer algo forzado y torpe el verso 11, los extraños rastros aplicados al archiconvencional dolor físico y moral del amante y a las flores que brotan en las huellas de los pies de Clori, señalan la belleza y la verdad poética del verso final. Años más tarde (1602, 132, p. 205), Angélica se derriba del palafrén, no porque al moro conoce, / sino por ver que la hierba / tanta sangre paga en flores, con el mismo remate y la misma juntura al final de la quinta cuarteta, pero con la metamorfosis de la sangre del joven moro en flores. Otro ejemplo, el de la canción de 1590 (78, p. 113-116), muestra una especial atención al ritmo ternario del verso final de cada una de las cinco estancias. Uno de ellos (v. 34), el de la segunda estancia, termina con flores: ven pompa, visten oro, pisan flores, haciendo eco al verso 17: ver a Dios, vestir luz, pisar estrellas y anunciando los siguientes, v. 51: vida a ti, gloria al Betis, luz a todos, v. 68: larga paz, feliz cetro, invicta espada y v. 85: la fe escudo, honra España, invidia el mundo. En 1607, cuatro textos, dedicados a la familia de Ayamonte, permiten apreciar el lugar privilegiado ocupado por flores, ya al principio del terceto final del soneto "Convoca los poetas de Andalucía a que celebren al marqués de Ayamonte":

flores a vuestro estilo dará el monte, candor a vuestros versos las espumas de Helicona darán, y de su fuente

ya al final del primer terceto de otro soneto, "A su hijo del marqués de Ayamonte, que excuse la montería”:

Deja el monte, garzón; poco el luciente venablo en Ida aprovechó al mozuelo que estrellas pisa ahora en vez de flores

ya al final de la décima cuarteta del romance "De la marquesa de Ayamonte y su hija”:

Ellas, en vano seguidas

de suspiros y de voces, el ciervo hacen, ligero, 
aljaba de sus harpones;

en cuyo alcance prolijo deben a sus pies veloces (a pesar de los coturnos), las selvas diversas flores

ya, último ejemplo, al final del soneto dedicado a la misma marquesa y a su hija:

si ya sus aras no les di terneros

dieron mis ojos lágrimas cansadas, mi fe, suspiros, y mis manos, flores.

Juega también Góngora con el paradigma rímico encabezado por flores, sea presentando el significante junto con uno de sus "compañeros de rima”, para decirlo con palabras jakobsonianas, sea sustituyéndolo una palabra en -ores en el remate del poema:

porque su sombra es flores, su dulce fruto dulces ruiseñores,

Aquí la primavera ofrece flores al gran pastor de pueblos, que enriquece de luz a España, y gloria a los Venegas.

Oh peregrino, tú, cualquier que llegas, paga en admiración las, que te ofrece el huerto, frutas, y el jardín, olores.

a vuestro hermoso pie cada cual debe lilios y rosas su beldad toda; ¿qué hará la mano si tanto puede el pie, que ostenta flores, por que vuestro esplendor venza la nieve, venza su rosicler, y por que en vano, 
hablando vos, espiren sus olores?

Último ejemplo de ese rápido repaso, las alegóricas dos décimas de "De la toma de Larache" juegan en sus versos finales con la paronimia mosquetes / mosquetas y la dilogía que estructura el poema entero. Entre las palabras pertenecientes al léxico militar, unas pueden remitir al bautizado y al bautismo (primera décima: africano / fuerte, ya que no galán, el africano cristianizado o la plaza fuerte; velas: barcos y cirios; escudos de oro: los que el padrino arroja en la ceremonia ${ }^{20}$ ), mientras que otras designan tejidos y telas finas (segunda décima: piezas, de tejido o cañones; Holanda: el país y el nombre de una tela fina). Sugerida de antemano por olores, en posición de rima consonante, la palabra flores, en posición final, se repite dos veces:
A la española el marqués
lo vistió, y dejar le manda
cien piezas que, aunque de Holanda,
cada una un bronce es.
Dellas les hizo después
a sus lienzos guarnición, [murallas]
y viendo que era razón
que un lienzo espirase olores, [tela fina]
oliendo lo dejó a flores,
si mosquetes flores son.
[arcabuces y, mosquetas, flores]

20 Antonio Carreira, Antología, p. 322. En "La especificidad del lenguaje gongorino", pp. 94-95, comenta: "Si el poema fuese de Ledesma, llevaría como subtítulo "en metáfora de un bautismo". Aquí la alegoría se mantiene sin decaimiento: Larache es un fuerte africano, y el término "fuerte" funciona a la vez como sustantivo y adjetivo; el marqués de San Germán lo hace cristiano, llevando diez velas al bautismo, con muchos escudos de oro: las diez galeras de la expedición, y los 120.000 ducados que según Cabrera se pagaron por la plaza al rey de Fez. El marqués lo vistió a la española, y le dejó cien piezas de holanda para guarnecer sus lienzos: las piezas de artillería, de origen holandés, que defendían sus muros, junto con mosquetes, palabra igualmente bisémica que significa 'arcabuces', y también 'rosas silvestres', aceptando la restricción de v. 20, porque en realidad la palabra idónea sería mosquetas". 
Otra vez llama la atención el poder que tiene flores, por su semantismo tanto como por su configuración fónica de conferirle a la escritura seudo heroica (bien se sabe que la "heroica" toma de Larache, en realidad, fue una compra), la suavidad o la dulzura de un estilo menos marcial ${ }^{21}$. Oportunamente, la lengua española le proporciona al poeta un término, lienzo, que tanto designa la dura muralla militar como el suave y delgado tejido, perfumado muchas veces y, no menos oportuna, sabe la escritura gongorina construir una delicada escala fónica y paronímica que de lienzo se eleva "naturalmente" a flores: un lienzo / espirase / olores / oliendo / flores hasta llegar al malicioso reparo final: si mosquetes flores son. Parece sugerir el último verso que, si la hazaña militar, desvirtuada por la tramitación económica, sufre la blandicia y afeminamiento de la referencia no militar de los vocablos, un leve fallo léxico impide que la suavidad, la iucunditas que suponen las flores, alcancen la perfección del estilo dulce: los mosquetes - por más que se parezcan los dos significantes- nunca serán mosquetas. De hecho, todo este final, tan florido, tan perfumado (espirar y olores suelen remitir a perfumes delicados ${ }^{22}$, así como oliendo a flores, aunque con el posible matiz 'pareciéndose a / haciendo pensar en flores'), si bien revela, concretándolo, el juego anfibológico que se mantiene a lo largo del poema, no deja de echar la acostumbrada mirada autorreflexiva sobre el trabajo poético: la paronomasia natural que acerca la mosqueta al militar mosquete ${ }^{23}$ - por la aspereza de sus consonantes, opuesta a la floral fragancia de su étimo, muscus, 'almizcle'-, mantiene la hibridación de un estilo de dos filos, ni heroico ni lírico, oliendo los anfibológicos lienzos a flores o a mosquetas, con tal que mosquetes flores sean. Lo que, pese a la casi perfecta homonimia, no son.

21 A propósito de la oposición asprezza / dolcezza en los teóricos italianos, en relación con la cuestión del hipérbaton, cf. Mercedes Blanco, "Góngora et la querelle de l'hyperbate", Bulletin Hispanique, Langue, Littérature, Littéralité, CXII, 1 (2010), pp. 169-217, y en especial pp. 195-196.

22 Por ejemplo el soneto "En la muerte de doña Guiomar de Sà, mujer de Juan Fernández de Espinosa", 1610, vv. 5-6: "El mismo que espiró süave aliento / fresca, espira marchita y siempre hermosa" (219, p. 299).

23 Palabra documentada en 1535 en España, según Corominas, del italiano moschetto. 
El ejemplo más perfecto y deslumbrante de cómo Góngora se vale de flores para cerrar una estrofa, una de las más bellas y debatidas de la Fábula de Polifemo y Galatea, es el que ofrece la octava 35²4:

De sitio mejorada, atenta mira en la disposición robusta aquello que si por lo süave no la admira, es fuerza que la admire por lo bello.

Del casi tramontado sol aspira a los confusos rayos, su cabello; flores su bozo es, cuyas colores, como duerme la luz, niegan las flores.

La rima, a la vez fónica y semántica, colores / flores, del pareado se refuerza con la figura de la epanadiplosis que, al colocar la palabra flores al principio y al final del cierre, sella el broche introduciendo, entre flores y flores, la mención a la vez perfectamente natural y enigmática de sus colores y la misteriosa justificación de su negación, por las mismas flores: como duerme la luz, niegan las flores.

En su magistral estudio del pareado, recuerda Jesús Ponce Cárdenas la versión parafrástica de Dámaso Alonso que relaciona la imprecisión de los colores del bozo con el hecho de que "el muchacho tiene cerradas las luces de sus ojos", impidiéndole a Galatea la falta de esa luz distinguir las "tonalidades" de las flores del bozo. Señala también la "secuencia lógica" que, en el comentario de Alexander A. Parker, vincula la octava 35 con la que sigue y en la que se da una agudeza de proporción con doble analogía: el cabello intonso de Acis es a la hierba sin cortar de la pradera (en que yace oculto / el áspid, 36, vv. 281-282) lo que el pelo bien peinado al jardín culto (v. 283), menos sugerente y sensual. Comenta Jesús Ponce: "la cabellera y la primera barba del fuerte joven constituyen dos rasgos de un insidioso atractivo que logra captar por completo la atención de la inadvertida nereida” (p. 93). Aduce también la fina y erudita observación

24 En la versión de Jesús Ponce Cárdenas, ed. cit. de la Fábula, pero restableciendo la preposición 'de', del casi tramontado..., al principio de v. 277, como en Dámaso Alonso, Carreira y Micó. Excusado es decir todo lo que estas líneas deben al suntuoso estudio "1.6.5. El lenguaje oculto de las flores: concepto, argucia y seducción" de Cinco ensayos polifémicos, pp. 92-109. 
de José María Micó que no deja de notar la extraña explicación de por qué no se ven claros los colores del bozo:

describe el bozo incipiente del joven Acis con una metáfora (flores) que puede hallarse en Virgilio (Eneida, VIII, 160; IX, 181), Silio Itálico (III, 84) y otros autores más modernos, pero la originalidad -y la dificultaddel pareado está en la curiosa explicación de por qué no se distinguen bien las tonalidades de ese bozo florido. La luz es la de los ojos de Acis: aquella duerme porque éstos están cerrados y, en consecuencia, las flores no dejan ver (niegan, 'ocultan', por la falta de luz) sus colores ${ }^{25}$.

Antes de proponer su propia teoría, cita Jesús Ponce la "explicación bastante innovadora del dístico" de Thomas Austin O'Connor ${ }^{26}$ que, en sustancia, se separa primero de la doxa interpretativa proponiendo que la luz no sea solo la de los ojos del mancebo dormido sino también la claridad de la inteligencia de Acis, que no se le manifiesta a Galatea, ya que ella no entiende el mentido / retórico silencio del fingido sueño de Acis (33, vv. 259-260). Sin que "llegue a ser del todo precisa" (como nota Jesús Ponce) la "atribución de sujetos", O’Connor percibe una sutil dilogía en flores: "Los colores del bozo niegan, ocultan, disimulan las flores, los galanteos y cortesías obsequiados por Acis [...] que tienen por objeto ganarse el amor de ella. Por eso, el período gramatical comienza con «flores», una metáfora convencional, y termina con «las flores» señalando y enfatizando dos tropos retóricos: epanadiplosis y antanaclasis". Equívoco también es el vocablo colores que, además de su referencia común (las "tonalidades" de Dámaso Alonso) remite, según enumera O’Connor, a las nociones de "pretexto, motivo, razón aparente para hacer una cosa con poco o ningún derecho”. En esos caminos de la dilogía, es innegable el aporte de ese estudio. Volveré más adelante a comentar otra observación del mismo O'Connor, que pasa desapercibida y que él mismo no comenta ni desarrolla.

25 José María Micó, El Polifemo de Luis de Góngora. Ensayo de crítica e historia literaria, Barcelona, Península, 2001, pp. 62-63.

26 Thomas Austin O'Connor, "Sobre el bozo de Acis: una apostilla a los versos 279-280 del Polifemo de Góngora”, Boletín de la Biblioteca Menéndez Pelayo, LXVIII (1992), pp. 143-148. 
En la base de los juicios aquí resumidos, propone Jesús Ponce una impresionante "lectura en anamorfosis" del dístico, "como en aquellos cuadros donde el espectador, al cambiar el ángulo de visión, percibe una imagen sorprendente e inusitada" (p. 95). No se puede resumir, sin desfigurarla ni empobrecerla, tan sutil, erudita y aclaradora exégesis, a la cual conviene referirse en su totalidad. Me contentaré con exponer sus hallazgos más relevantes. Tras evocar, a propósito de las flores del bozo, los "caminos de la polisemia" y el valor de trampa y engaño de flor en diccionarios y textos literarios, y tras dilucidar con San Bernardo, Lope de Vega y Antonio de Eslava la "retórica del silencio", saca Jesús Ponce, fundándose en una observación precisa de las estrofas 33 a 35, unas primeras conclusiones:

Al desconocer las añagazas del amor y sus discursos seductores, Galatea se muestra "bárbara al mentido / retórico silencio que no entiende". Por todo ello, si tratamos de enlazar en una isotopía coherente el arco de unión que comprende el haz de elementos formados por el mentido retórico silencio, las flores y los colores, quizá sea lícito considerar que el silencioso discurso visual que le ofrece Acis desde su yacente figura cuenta entre sus principales galas con el ornato viril de su bozo, elemento que viene a ser algo así como las "flores" de tal discurso, el adorno pertrechado de "colores" retóricos destinados a mover los afectos de tan huidiza destinataria [...].

Precisamente por ello, se nos antoja necesario que sea la ninfa, en tanto objeto o presa de las artimañas seductoras, aquella que presente anulada en ese momento la luz del entendimiento. A mi entender, el narrador está subrayando aquí la admiración de la nereida ante los atractivos del joven: la bella esquiva, de hecho, queda obnubilada ante los encantos del varón y dicho arrobamiento anula su capacidad de discernir el peligro inherente a la situación real. La luz del entendimiento, la luz de la prudencia de Galatea, se muestra dormida en ese preciso instante (pp. 100-101).

Sacando a colación loci paralleli de Cervantes, fray Vicente de Burgos y el propio Góngora que confirman su interpretación de como duerme la luz, pasa a preguntar el exégeta por qué resulta el primer vello de Acis una trampa. La respuesta la encuentra tanto en Juan de Valdés o Gonzalo Correas como en el libro de Francisco Delicado: Guárdate del mozo cuando le nace el bozo, reza el refrán, advirtiendo que la señal del bozo es 
indicio de "la pujanza erótica propia de la juventud" (p. 104). Ya pertrechado de testimonios y observaciones, se propone Jesús Ponce recorrer "Los ambivalentes senderos del ingenio: dilogía, redditio y antanaclasis" (1.6.5.4.), señalando en un cuadro la(s) valencia(s) semánticas que pueden asumir en el dístico los núcleos nominales, en el orden de su aparición:

flores $=$ 'flores'

colores = 'tonalidades' / 'refinamientos', 'insidiosas sutilezas'

duerme la luz = 'Acis tiene los ojos cerrados' / 'obnubilado el entendimiento de la ninfa'

flores = 'flores' / trampas en el juego de la seducción'.

Pasa entonces a formular las dos interpretaciones que se hallan coexistentes en un solo y mismo dístico (pp. 105-106) y concluye:

De resultar aceptable la hipótesis de esta lectura anamórfica de las flores del bozo, no deja de resultar fascinante que mediante el recurso léxico propio de una ambivalencia significativa el poeta haya logrado engarzar conceptualmente varias estancias que comparten la isotopía de lo discursivo ("mentido retórico silencio" / "flores" / "colores"), lo falsamente seductor ("retórico" / "colores" / "luz" / "flores"), lo escondido ("no entiende" / "niegan" / "yace oculto").

Me parece evidente que no solo es “aceptable” la lectura de Jesús Ponce, sino que se impone por el rigor del análisis léxico, semántico y textual y por fundarse en una observación precisa e inteligente del conjunto de las tres octavas 33, 34, 35. En efecto, al poner de relieve el hilado fino o, más bien, el sutil trenzado de tres hilos ("lo discursivo", "lo falsamente seductor" y "lo escondido") que afianza la perfecta coherencia semántica del conjunto -y abarcando también, con yace oculto, la octava 36, con la clave del silente discurso retórico del cuerpo de Acis, el áspid disimulado entre las flores ${ }^{27}$ cabello (y del bozo) - la hipótesis interpretativa de

27 Llama la atención el uso que hace Góngora del tópico del latet anguis no ya in herba sino entre flores, especialmente cuando evoca la flor de la edad o la juventud floresciente amenazada por el áspid de la muerte. Un ejemplo: "Moriste, ninfa bella / en edad floresciente / que la muerte entre flores / se esconde cual serpiente" (En la muerte de doña Luisa de Cardona, 1594, 103, p. 161). También lo usa, en el mismo contexto de las flores de los años, para evocar el ocio que podría impedirle al joven don Diego Paez escribir poesía: "No entre las flores, no, señor don Diego, / de vuestros años, 
Jesús Ponce me parece fundarse -si bien no lo dice- en un rasgo insistente de la escritura gongorina: el condicionamiento de la lectura. En los poemas de madurez, raras veces le cogen desprevenido al lector las fórmulas más novedosas, complejas o atrevidas, con la condición inexcusable de que le preste la atención más estricta a la letra de los textos. De ahí que resulte indispensable tomar en consideración el contexto en el que se inscribe la fórmula para dar con la clave de una lectura apropiada, justa: solo la percepción de los tres hilos en el conjunto de las tres octavas permite dar cuenta de las dilogías observables en el dístico. Digamos, para abreviar que, para apoyar su interpretación de como duerme la luz, Dámaso Alonso tiene en mente el último verso de la octava 32: fingiendo sueño al cauto garzón halla y el primero de la 33: El bulto vio y, haciéndolo dormido. Para proponer su novedosa intuición, O'Connor se fija en otro campo semántico que el del sueño: el de la retórica del silencio. Y finalmente, Jesús Ponce, rectificando errores, profundizando en esa intuición, descubriendo más indicios y consultando con diccionarios y otras obras literarias, nos brinda la bella y acertada lectura que acabo de presentar ${ }^{28}$.

En un punto discrepo de Jesús Ponce: en la calificación de su lectura como anamórfica, ya que tanto la explicación de Dámaso Alonso y José María Micó por una parte, como la de Parker, O’Connor y la suya propia por otra, tienen por fundamento indicios exteriores a la octava 35. El punto de vista, o el "ángulo de visión”, me parece ser el mismo: indagar fuera de la octava la clave de sus enigmas, y acertar, revelando la clarísima demostración que el denso dístico constituye el clímax no solo de una estrofa sino de una serie de octavas. La epanadiplosis Flores... las flores, con el enlace de sus colores, ilustra con flamante valentía, valiéndose el poeta de las figuras de la repetición y diáfora, así como de la plasticidad referencial previamente definida de flores y colores en el campo de la retórica, la notable aptitud del significante flores para darle sutil y brillante remate a la construcción dilatada, diferida de un concepto.

áspid duerma breve: / el ocio, salamandria más de nieve / que el vigilante estudio lo es de fuego. [...] // Escribid [...]". (A don Diego Paez de Castillejo, 1615, 287, p. 449). 28 Cf. también en su edición del Polifemo, Madrid, Cátedra, 2010, "Introducción”, el análisis de "este jardín de conceptos que se bifurcan" (pp. 104-106) y las notas a la octava XXXV, pp. 288-290. 
Si se habla de anamorfosis, imagino que otro ángulo de visión habría que buscar. Me propongo, pues, junto a la mirada amplia y abarcadora, elegida por Jesús Ponce, intentar aplicarle al dístico un ángulo de visión estrecho, restringiéndolo no solo a la octava 35 sino a sus últimos cuatro versos y, más aún, al dístico final. De experimentar se trata, pero sin renunciar a la magnífica y doble interpretación previamente expuesta. No es nada fácil la empresa, menos exaltante, más ingrata que la exploración de la pareja texto/contexto, reduciéndose esta, en el dístico, a la ecuación: texto $=$ contexto. Volviendo a leer el pareado, flores su bozo es, cuyas colores I como duerme la luz, niegan las flores y procediendo por etapas sin salir de su cerrado recinto, al menos hasta la "curiosa explicación” (Micó) del inciso como duerme la luz, se me ocurren una cuantas observaciones:

flores su bozo es: fiel al procedimiento que consiste en condicionar la lectura, propone el pareado una proporción, una ecuación (flores $=$ bozo), cuyo carácter tópico -si bien no se niega- se matiza algo por el énfasis sintáctico que consiste en anteponer el segundo término de la ecuación, flores (aquel que en una comparación sería el comparante), al objeto (el bozo) que funda la proporción. Al surgir al principio del verso, flores (como bien apuntó Jesús Ponce) significa 'flores', se supone que botánicas, aunque el pasmo producido por su violenta irrupción quizás solo permita que se perciba el propio significante, momentáneamente libre de cualquier predefinición contextual;

cuyas colores: de inmediato surge una duda. ¿Cuál es el antecedente del relativo posesivo cuyas?: ¿flores?, ¿bozo? Desde un punto de vista interpretativo, puede parecer indiferente que se atribuyan las colores a las flores o al bozo, ya que flores es el bozo. En realidad, es cierto que la palabra que atrae, por evidente afinidad semántica y semiótica, la rima colores no puede ser sino flores, manteniéndose así, a pesar de la ecuación flores = bozo, el irisado referente botánico. Sin embargo, y así lo entendieron prestigiosos comentaristas, la proximidad de cuyas con bozo induce la lectura: colores del bozo. También se bifurcan los caminos sintácticos... y tendremos en cuenta esa bifurcación a la hora de comentar niegan las flores. 
como duerme la luz: ahí está la dificultad, señalaba José María Micó, subrayando lo curioso de una explicación que lo complica todo. De hecho, lo que complica es el verbo duerme y la posible inscripción de luz en contextos literalmente cronográficos y 'luminosos' o, en sentido figurado, en el contexto intelectual del conocimiento y entendimiento. Imaginemos un instante que, en vez de duerme haya elegido el poeta otro verbo: falta la luz, por ejemplo. Nos llevaría esa 'falta' de luz a buscar, en el contexto inmediato, los motivos o las condiciones verbales y poéticas de ese oscurecimiento. No sería necesario alejarse de la octava, ni del dístico, para encontrarlos. Están precisamente en los dos versos inmediatamente anteriores: del casi tramontado sol aspira, / a los confusos rayos su cabello. Para disipar de antemano cualquier confusión, puntualicemos que esa magnífica y sutilísima escena de voyeurismo en su conjunto no se sitúa en las horas crepusculares sino en pleno mediodía y en la Canícula. La mención del crepúsculo sirve para describir el intonso cabello de Acis que aspira al color de los confusos ('indistinctos' según Salcedo Coronel) rayos del casi tramontado sol. Inútil es repetir los comentarios antiguos y modernos a estos versos y los matices prestados al color del cabello del joven: castaño, entre negro y rubio, entre claro y oscuro, rubio ceniza, dorado oscuro, castaño claro, flavo... El razonamiento es casi matemático: siendo la falta de luz crepuscular la que impide que se distingan claramente los indistintos rayos del sol cuando está a punto de desaparecer tras el monte, y pareciéndose el cabello de Acis a esos rayos ya casi oscuros, el bozo / flores, del mismo color crepuscular que el cabello (con un "salto" si no "ecuestre", racional o lógico), sufre idéntica falta de luz. La poesía de Góngora ofrece notables casos, serios o jocosos, y sublimes, de la escritura de ese confuso momento crepuscular, verdadero "oxímoron" natural, en que es luz la oscuridad y tinieblas la claridad ${ }^{29}$, pero es la única vez en que un comparante (el color del cabello es como los confusos rayos del casi tramontado sol) parece extender su radio de acción más allá de la estricta comparación, determinando asimismo los colores (también apagados) del bozo. Exige tal transgresión, mejor dicho tal elipsis del

29 Uno de los más llamativos es el de las octavas de Al favor que San Ildefonso recibió de Nuestra Señora [...] (Carreira, 310, pp. 475- 477): "Era la noche, en vez del manto obscuro / tejido en sombras y en horrores tinto, / crepúsculos mintiendo al aire puro, / de un albor ni confuso ni distinto" (p. 475). 
eslabón intermediario, una explicación, aunque se fuerce algo el contenido exacto del pareado: como se parece el cabello de Acis a los confusos rayos, faltos de luz, del casi tramontado sol, la misma falta de luz afecta al bozo, impidiendo que se distingan netamente los colores de sus flores. Pero el genial Góngora echa mano del verbo dormir, ya usado anterior y literalmente a propósito de Acis dormido, borrando así las fronteras entre la lectura del solo dístico y la memoria lectora que hace que se remonten a flor de texto fragmentos anteriores, en que la luz dormida es la de los ojos del mozo y también la ceguera de la fascinada Galatea. Mantengamos, pese a la atracción que ejerce la visión contextual amplia, el rumbo de la lectura estrictamente limitada al pareado, pero antes de examinar su último sintagma, rindamos el homenaje previsto a Thomas Austin O'Connor que en su "apostilla a los versos 279-280" evoca la posibilidad de que luz tanto remita a los rayos del casi tramontado sol como a la luz del entendimiento (es mía la cursiva): "La luz resulta ser una dilogía que se refiere tanto a la luz del sol poniente como a la inteligencia de Acis". Rindamos asimismo homenaje a la fina intuición de Pellicer ${ }^{30}$ que, antes de evocar la luz dormida de los ojos de Acis e imaginar un vello más bien ralo, elabora una comparación que, a todas luces, le dicta la compleja compostura de los versos gongorinos:

Todo este lugar trasladó en la Soledad I... Toma la metáfora de que las flores quando el sol duerme, o se pone, se encogen hasta que amanece, y no muestran el color que tienen, assí Acis dormido, no permitía que se viesse la color del boço: o era tan poco el boço de Acis, que no se distinguía estando dormido.

flores su bozo es, cuyas colores, / como duerme la luz, niegan las flores: formando parte el sintagma final, niegan las flores, de la subordinada de

30 Proviene la cita de Antonio Vilanova, Las fuentes y y los temas del Polifemo de Góngora, Madrid, Anejo LXVI de Revista de Filología española, 1957, II, p. 248. En el mismo lugar, el comentario de Salcedo Coronel recuerda el de Pellicer: "Cuyas colores no se distinguen, como duerme la luz de sus ojos. Válese desta Metáfora de la luz, y de las flores para significar que era tan poco el bozo de Acis, que no se podía conocer estando dormido, de la suerte que faltando la luz del Sol, no se diferencian las colores de las flores (fol 373-373 v.)". 
relativo introducida por cuyas, no se puede excusar la cita completa del dístico. No se limita la hipótesis de que se bifurca la sintaxis a la subordinada de relativo posesivo sino que concierne también a la atribución de las funciones de sujeto y objeto a colores y a flores pudiendo leerse la oración de dos maneras: 1. flores su bozo es, cuyas colores (colores de las flores, complemento directo de niegan), como duerme la luz, niegan las flores (sujeto de niegan); 2. flores su bozo es, cuyas colores (colores del bozo, sujeto de niegan), como duerme la luz, niegan las flores (complemento directo de niegan). No se trata ya del "jardín de conceptos que se bifurcan” (Jesús Ponce) sino de un verdadero laberinto, cuidadosamente diseñado, y perfectamente cerrado por las flores iniciales y finales. En el primer caso, el sentido sería: su bozo es [como] flores [naturales, vegetales] cuyos colores [naturales y varios], como duerme la luz [del casi tramontado sol de su cabello y bozo], niegan [son negadas por] las [metafóricas] flores [del bozo]. En el segundo caso, más sobrio, el sentido, muy parecido, podría ser: [como] flores [vegetales] es su bozo, cuyos colores [del bozo], como duerme la luz [del tramontado etc.], son los que niegan [excluyen] las flores [naturales]. En ambos casos se cuestiona el tópico de las flores del bozo o, más bien, se enfocan las consecuencias discursivas del tópico, introduciéndose en el primero una dilogía entre las flores naturales y las flores metafóricas del bozo que, faltas de luz por la mención del tramontado sol, excluyen los colores de las flores botánicas; en la segunda hipótesis, se mantiene la referencia a las flores naturales, al principio y al final del dístico, pero los colores del bozo son los que a posteriori señalan que las flores de la ecuación tópica no pueden ser las naturales o vegetales.

Consiste la ingeniosa y paradoja agudeza en proponer una proporción ( flores $=$ bozo), dificultarla con un artificioso equívoco y un significar a dos (o más) luces (cuyas colores [...] niegan las flores) y de la misma paradoja hacer desempeño dándole el fundamento de una razón misteriosa (como duerme la luz) ${ }^{31}$.

31 Se inspira claramente esa conclusión en forma de popurrí en Baltasar Gracián, Agudeza y arte de ingenio, ed. de Ceferino Peralta, Jorge M. Ayala y José M. a Andreu, Zaragoza, Prensas Universitarias de Zaragoza, Huesca, Instituto de Estudios Altoaragoneses, 2004, 2 vols, y en particular, en el vol. 1, los Discursos VIII y XXIII a XXV. 
Si se acepta esa lectura, y si se consiente en asociar su estrecho ángulo de vista a la interpretación de Jesús Ponce, entonces sí disponemos de una lectura anamórfica del fragmento que, según se mira y analiza, ofrece "una imagen sorprendente e inusitada" (Ponce, p. 95): la de una agudeza que, a modo de enigmática cifra, corona una serie de octavas, recogiendo y abreviando en poco espacio los indicios que permiten diversificar el significado de colores y flores; la de una agudeza restricta que juega con los significantes colores y flores sin salir de los campos semánticos -vegetal I no vegetal- impuestos por la equivalencia flores su bozo es. Además, hace eco la interpretación en anamorfosis del cierre de la octava 35 a la composición global de la fábula en la que cada octava compone un "todo", perfilado por su estructura formal y temática, inserto en el movimiento general del epilio y enlazado, por medio de indicios léxicos, a varias partes del conjunto poético.

Valgan, para terminar y a modo de transición con el último apartado de este estudio, tres ejemplos más de evocación poética del bozo, dos de ellas sencillas, la tercera más compleja por recordar la estrofa del Polifemo. En el famoso romance de 1596 (Carreira, 109, pp. 169-172), famoso por presentar rimas consonantes en los versos pares (como apunta el mismo Góngora), se dirige el poeta monigote a los galanes vasallos del amor:
Galanes los que acaudilla
el del arco y del virote, o tengáis el bozo en flor o en espinas el bigote, escuchad los desvaríos de un poeta monigote en cuarenta consonantes destilados del cogote;

Recordando la joven valentía del "Conde de Lemus, habiendo venido nueva de que era muerto en Nápoles” (1614, 273, pp. 428-430) en una canción inacabada, lo pinta Góngora en el robusto ejercicio de la caza, dándole alas al caballo y rojas plumas de sangre al espolearlo:

Cuando de flores ya el vulto se viste, al fogoso caballo Valenzuela 
purpúreas plumas dándole tu espuela, en el oficio duro de la robusta caza, las riberas del Sil te vieron fatigar las fieras.

Pero el fragmento de más interés, aludido por Pellicer en su comentario al lugar de la estrofa 35 del Polifemo, trasladado a la Soledad primera, es el que concierne al novio de las bodas rústicas (vv. 769-772). De hecho, lo que se traslada aproximada o literalmente de la fábula a la silva es una "constelación" 32 de palabras: cabello intonso, niega, colorido, primavera, rayos, cabello, vello en vez de bozo y flores, cuya reorganización sintáctica y semántica bien podría echar una luz sobre el pareado del epilio:
"Ven, Himeneo, ven donde te espera, con ojos y sin alas, un Cupido cuyo cabello intonso dulcemente niega el vello que el vulto ha colorido:
el vello, flores de su primavera, y rayos el cabello de su frente ${ }^{33}$.

En ambos textos, el bozo y el vello aparecen negados, aquí por el cabello intonso ${ }^{34}$, allá (si se acepta mi lectura) por sufrir el bozo el impacto semántico de la luz dormida del casi tramontado sol y del color apagado, semioscuro, del cabello parecido a los confusos rayos del sol poniente. Es obvia la originalidad del color atribuido al cabello de Acis en la Fábula: oro y rayos solares, por cierto, pero oscurecidos por la mención del casi tramontado sol. En ambos casos, lo que parece importarle al poeta es

32 Los que trabajamos en cosas del lenguaje, le debemos la fórmula y la noción a Gilbert Durand, en su clásico libro Les structures anthropologiques de l'imaginaire, Paris-Bruxelles-Montréal, Bordas, 1969.

33 Cito por la edición de Robert Jammes, Madrid, Castalia, 1994, pp. 351-353.

34 En la nota correspondiente a los vv. 769-770, da cuenta Robert Jammes de las dos lecturas posibles del fragmento: “"Su largo pelo infantil desmiente el vello que cubre su rostro", dice Jones (p. 141), dando a niega su sentido figurado habitual, mientras Salcedo, seguido por D. Alonso y por Carreira, lo interpreta de modo más concreto: "cuyo cabello no cortado encubre el vello que da color a su rostro" (fo. 158). Yo también he adoptado esta solución [...]” (p. 350). 
una paradoja: afirmar la presencia de los colores y flores del bozo como colores y flores de la primavera juvenil, negándolos. Pero mientras que en la Soledad la doble equivalencia vello = flores y cabello = rayos se $\mathrm{da}$ como complemento de la expresión literal, en el Polifemo van tan estrechamente intrincadas la dicción literal y la metafórica que la densidad de la escritura produce la meraviglia, el pasmo ante la (aparente) opacidad del significante flores. Repitiéndose al principio y al final del pareado que cierra la octava, imponen las flores en la escritura poética de Góngora (y cualesquiera que puedan ser las bifurcaciones referenciales sugeridas por el contexto) la materialidad de su presencia gráfica, sonora y emblemática: la de un núcleo verbal de excepcional calidad semiótica.

\section{Correspondencias E IMANTACiONES SEMÁNTICAS Y SEMIÓTICAS EN TORNO A FLOR}

Abrevia, en efecto, el significante flor, como si fuera un pictograma precioso o una brillante gema fonosimbólica -y eso en cualquier contextola calidad de cuanto seduce y halaga, exalta y da gusto. Signo del placer de los sentidos y de la escritura, surge -admirablemente anunciado- al final del emocionado y encomiástico soneto $A$ Córdoba (1585, 50, p. 60):

¡Oh excelso muro, oh torres coronadas

de honor, de majestad, de gallardía!

Oh gran río, gran rey de Andalucía, de arenas nobles, ya que no doradas!

¡Oh fértil llano, oh sierras levantadas, que privilegia el cielo y dora el día!

¡Oh siempre gloriosa patria mía, tanto por plumas cuanto por espadas!:

Si entre aquellas rüinas y despojos que enriquece Genil y Dauro baña tu memoria no fue alimento mío, 
Nunca merezcan mis ausentes ojos

ver tu muro, tus torres y tu río,

tu llano y sierra, ¡oh patria, oh flor de España!

Andrés Sánchez Robayna, en un bello estudio titulado "Córdoba o la aurificación”, observa que la reiteración de la sílaba -or- en el soneto "remite, además, a una clara alianza de sonido y sentido. -Or - es, como se ha visto, la reticulación o condensación sonora de Córdoba. Pero en la palabra Córdoba está la palabra oro" (p. 81): por eso, a las once recurrencias de la sílaba 'dorada' subrayadas por Sánchez Robayna, en cursiva en el texto aquí reproducido, me ha parecido conveniente añadir la forma latina de -or - $\mathrm{u}$-oro en el también aurificado nombre del río Dauro, "llamado precisamente así por llevar oro" (p. 81). Ahora bien, culmina la última representación de la sílaba, hipograma de la construcción fonosimbólica del soneto (p. 79), en la eclosión, en el último verso, del monosílabo agudo flor. Precedido por la figura de la correlación diseminativorecolectiva que recoge en los vv. 13 y 14 los anteriormente sembrados en los cuartetos muro, torres, río, llano y sierra, el significante pictográfico y fonético flor abrevia en su única sílaba las doce "gotas de luz" 35 asimismo diseminadas por el soneto, de -or-, "aquella sola sílaba fulgurante", cifra y emblema de la ciudad de Córdoba (p. 81). Como en lejano eco a las abundantísimas flores doradas de la poesía medieval y renacentista, pero en singular, hace surgir el crisol del soneto la luminosa isotopía entre oro y flor, sustentada por la configuración natural de las palabras y el resplandor de la luz encerrada en el metal precioso y como desplegada por la corola floral.

Al iniciar esta reflexión llamé 'florida' la escritura del Góngora maduro por motivos de simple aumento de la frecuencia de flor(es). De hecho, la multiplicación es un rasgo relevante de su escritura floral, ya se nombren en plural las flores; ya se propongan, por medio de una doble proporción, correspondencias entre las flores y otros elementos, tan bellos e innumerables como ellas; ya se repita el significante; ya florezcan en torno a flor(es) rimas y parónimos que prolongan el efecto placentero, la iucunditas, que

35 Gilbert Durand, op. cit., p. 166: "L'or, grâce au doré, est bien "goutte de lumière»", remitiéndose la fórmula, en la nota 7, a Lanza del Vasto, Commentaires des évangiles, p. 137. 
le infunde al poema y le produce al lector la aparición del pictograma sonoro. Muestra de ello, la canción de 1602, Vuelas oh tortolilla (128, pp. 199-200), en su tercera estancia y en solo seis versos repite cuatro veces el verbo contar, encareciendo la constancia, paciencia y envidia del amante desechado, capaz de contar, una a una las quejas y ciento a ciento los besos de las tórtolas enamoradas, tan incontables como las flores en la primavera:

Mi piedad una a una contó, aves dichosas, vuestras quejas sabrosas; mi invidia ciento a ciento contó, dichosas aves, vuestros besos süaves. Quien besos contó y quejas, las flores cuente a mayo y al cielo las estrellas rayo a rayo.

Hemos visto que en buen número de composiciones expresa o exprime (hace brotar) la palabra flor la cima de la delicia: multiplicándose, multiplica las delicias, del mismo modo que, en la canción de 1612, A los poetas que asistian en Ayamonte (256, pp. 352-353), las flores trasladando de su boca I a la sacra vihuela, I dulzuras acrecientan a dulzuras. En las líneas que siguen, se comentan unos ejemplos de correspondencias, repeticiones y atracciones paronomásticas que ilustran la vertiente floral de la escritura de Góngora.

\subsection{Imantaciones semánticas}

Aparece la tradicional correspondencia entre flores y estrellas en doce poemas (incluyendo la canción ya citada Vuelas oh tortolilla). Escasa antes de 1600 , cunde entre 1600 y 1621. Lo mismo se puede decir de la correspondencia entre flores y rayos (un caso antes de 1600, once entre 1602 y 1621) mientras que, no por escasas menos interesantes, una serie de "armónicas correlaciones" ${ }^{36}$ entre flores por una parte, ruiseñores, panales,

36 Baltasar Gracián, Agudeza, Discurso II, p. 27. 
centellas, arenas o espumas y aplausos, por otra, proponen ingeniosos "careos" y poéticas agudezas ${ }^{37}$. No siempre es invención de "aquel que fue cisne, fue águila, fue fénix, en lo canoro, en lo agudo, y en lo estremado"38 la red de esas concordancias analógicas propias de una cosmovisión en que la belleza y el esplendor se repiten, revistiendo formas específicas y comparables, en los distintos elementos del mundo universo. Sin embargo, el repaso que hemos hecho revela unos hallazgos y una puesta en tela de juicio de ciertas asociaciones tópicas dignos de señalarse.

En plural y en la frente de alguna que otra ninfa, las flores, en guirnalda o en corona, participan de dos dobles proporciones. Cuando se trenzan en guirnalda, son a las sienes bellas lo que las estrellas de la guirnalda celeste, las luces nueve de la constelación de Ariadna ${ }^{39}$, son al cielo (Soneto

37 Flores/estrellas en: 1582, 15, p. 22, Al tramontar del sol; 1588, 74, p. 103, Desde Sansueña a Paris; 1600, 120, p. 183, Al marqués de GuadalCazar; De las damas DE PALACIO; 1602, 128, p. 199, Vuelas, oh tortolilla; 1603, 135, p. 209, PARA LO Mismo (En el Sepulcro de la DuQuesa de Lerma); 1607, 171, p. 235, Al hijo del marQués De Ayamonte, Que excuse la montería; 1610, 219, p. 299, En la muerte de doña Guiomar de SÁ; 1612, 256, p. 352, A los poetas que asistían en Ayamonte; 1615, 292, p. 452, En la muerte De tres hijas Del DUQUe de Feria; 1617, 313, p. 482, v. 112, Panegírico al duque de Lerma; 1620, 351, p. 548, vv. 29-32, En la fuerza de Almería; 1621, 370, p. 567, vv. 25-28, En PERSONA DEL MARQUÉs Flores DE Ávila, estando enfermo. Flores/rayos en: 1582, 14, p. 21, Tras la bermeja Aurora el Sol dorado; 1602, 128, p. 199, Vuelas, oh tortolilla; 1603, 135, p. 209, PARA lO Mismo (En el sepulcro de la duQuesa de Lerma); 1612, 253, p. 335, Para un libro del Licenciado Soto de Rojas; 1612, 255, p. 345, vv. 277-280, Fábula de Polifemo y Galatea; 1613 , 264, Soledades, vv. 250, 755-760, 771-772, Soledad Primera; 1614, vv. 306-307, Soledad SEgunda; 1615, 299, p. 461, Para lo mismo (En el nacimiento de Cristo nuestro señor) ; 1620, 347, p. 540, Del REY y REINA NUESTROS SEÑORES en Aranjuez, ANTES DE REINAR; 1621, 370, p. 567, vv. 25-28, En persona del marqués Flores de Ávila, estando enfermo. Flores/ruiseñores en: 1598, 114, p. 177, Donde las altas ruedas; 1609, 213, p. 290, No son todos ruiseñores, 1609, 202, p. 274, ; Mal haya quien en señores idolatra! Flores/heridas y panales en: 1608, 183, p. 263, De la florida falda. Floreslespumas y flores/arenas en 1612, 255, vv. 128 y 502, Fábula de Polifemo y Galatea. Flores/centellas en: 1614, 282, p. 441, v. 22, EN LA beatificación de santa Teresa. Floreslaplausos en: 1622, 384, p. 579, Para doña María Osorio, mujer de don Antonio Chacón.

38 Baltasar Gracián, Agudeza, p. 35.

39 Otra constelación del zodíaco (el Capricornio) es la que, fundada en el modelo de la fórmula de flores estrellado, aparece en los vv. 302-307 de la Soledad segunda: 
de 1582, Al tramontar del sol la ninfa mía $)^{40}$. Si coronan la frente de la aurora o de un poeta, les son las flores lo que sus rayos al sol: equivalencia no tan original como significativa del proceder del poeta que dispone de paradigmas ${ }^{41}$ verbales, semejantes a acordes de música, a paletas de pintores o a constelaciones de palabras, relativamente fijos y lo suficientemente flexibles como para repetirse, íntegra o parcialmente, en poemas siempre distintos, siempre nuevos. He aquí unos ejemplos:

Tras la bermeja Aurora el Sol dorado

por las puertas salía del oriente,

ella de flores la rosada frente,

él de encendidos rayos coronado;

Complicando el paradigma con el floreo de la agudeza nominal, los tercetos del soneto Para un libro del Licenciado Soto de Rojas convierten al poeta - predefinido por su nombre- en nuevo sol apolíneo cuyos rayos son flores rojas:

Él, pues, de rojas flores coronado, 1612 nobles en nuestra España por ser Rojas, como bellas al mundo por ser flores,

con rayos dulces mil de Sol templado al mirto peina, y al clavel las hojas,

"Llegaron luego donde el mar se atreve, / si promontorio no, un cerro elevado, / de cabras estrellado, iguales, aunque pocas, / a la que - imagen décima del cielo- / flores su cuerno es, rayo su pelo".

40 Nótese de paso el "trenzado" algo diferente que presenta, tejido con los hilos de las mismas palabras (flores, frente, estrellas, guirnalda griega, corona), el soneto de 1603, en forma de epitafio en primera persona, En el sepulcro de la duquesa de Lerma. Nótese también cómo la guirnalda pasa a ser corona: ceñi de un Duque excelso, aunque flor bella, / de rayos más que de flores frente digna (vv. 3-4); Estrellas son de la guirnalda griega / lisonjas luminosas, de la mía / señas oscuras, pues ya el sol corona (vv. 9-11).

41 Esa noción, lingüística, la debemos los que fuimos sus alumnos, a la docencia de Mauricio Molho, también destacado gongorista que nos enseñó -sin descartar fuentes ni modelos- a tomar en cuenta la literalidad de los textos y a comentar las figuras retóricas a la luz de la gramática. 
monte de musas ya, jardín de amores.

En la estación florida de la Soledad primera, en que no puede ser el aventurado albergue sino alquería de Flora, sacando partido de la permanencia de la proporción Aurora / flores $=$ Sol / rayos y de la fórmula sintáctica $S i$ $A$ no, $B$, señala una hipálage, al trastrocar los habituales atributos, las "sinonimias" e inversiones poéticas o nuevas junturas verbales, aceptables o desechables, propuestas por el paradigma:

De el verde margen otra las mejores rosas traslada y lilios al cabello, o por lo matizado o por lo bello, si Aurora no con rayos, Sol con flores.

Aplicándose flores y rayos tanto a la radiante novia solar: ella, la misma pompa de las flores, I la esfera misma de los rayos bellos, (vv. 759-760), como al novio, asimismo radiante y solar, con el bozo florido y el cabello tan esplendoroso como el pelo del toro celeste al principio de la silva: el vello, flores de su primavera, / y rayos el cabello de su frente (vv. 771-772). El hiperbólico encarecimiento de la belleza y de la luz, por medio de la repetición de las dos palabras, alcanza otra cima en dos poemas de 1620, una canción y un romance, ambos dedicados al rey y la reina antes de reinar. En el romance (347, Del rey y reina en Aranjuez, antes de reinar), los dos reales pastores, en figura de Belisa y Fileno (y en dos versos trenzados en forma de quiasmo y dos más, paralelos pero con quiasmo en el último), son tan igualmente bellos y luminosos que intercambian sus atributos:

pastores que, en vez de ovejas

y de corderos en vez,

rayos del sol guarda ella,

de abril guarda flores él.

Y en la canción (349), siendo Belisa un sol [que] con dos soles viene, dulce más que el arroyuelo / que las azucenas pisa (vv. 17-18), ya no es aquella cuyos pies, tradicionalmente, hacen brotar flores, sino que, al llegar la 
reina, de rayos se bordó el suelo; / y el zagal, I aunque es águila real, I su luz apenas sostiene.

Otra equivalencia, entre pisar flores y pisar estrellas se da, por ejemplo, en el soneto de 1607, A su hijo del marqués de Ayamonte, que excuse la montería, en que se aducen los ejemplos del malogrado Adonis y de Ganimedes, raptado por Júpiter, que estrellas pisa ahora en vez de flores, mientras que la difunta doña Guiomar de Sá, en el soneto de 1610: Ya en nuevos campos una es hoy de aquellas / flores que ilustra otra mejor Aurora / cuyo caduco aljófar son estrellas (vv. 12-14). Las tres hijas muertas del duque de Feria (en la canción de 1614), son flores celestes, estrellas: Tres vïolas del cielo, / tres de las flores ya estrellas. La trasmutación, sin embargo, no siempre necesita del paso de la tierra al cielo o de la vida a la muerte: estrellas fragantes son los jazmines del romance En la fuerza de Almería (1620) y, al aleccionar al marqués de Flores de Ávila, en la bella letrilla, Aprended, Flores, en mí, elige la maravilla — la más efímera de las flores-, el ejemplo del jazmín. En la mudanza que le dedica, se vuelve a componer el paradigma de significantes: flor / estrella / rayos, al que se añade el ámbar por la fragancia, repitiéndose excepcionalmente hasta cuatro veces el lexema flor en la estrofa y confirmándose juntamente la verdad poética, la verdad hortelana y la verdad referencial de la correspondencia y del estribillo $^{42}$ :

Flor es el jazmín, si bella, no de las más vividoras, pues dura pocas más horas que rayos tiene de estrella; si el ámbar florece, es ella, la flor que él retiene en sí. Aprended, Flores, en mi [...]

Y, último ejemplo de la juntura flores / rayos, el de una de las letrillas de 1615 Al nacimiento de Cristo Nuestro Señor, ¿Cuál podréis, Judea, dezir, con flores que brotan de la nieve y la espléndida metamorfosis

42 Al Marqués de Flores, gran amigo de Góngora, le gustaban las flores, como demuestra Robert Jammes (Luis de Góngora, Letrillas, pp. 22-23). 
del portal de Belén en zodíaco ${ }^{43}$, menos conocido éste tal vez que el zodíaco cristalino, recorrido por la nave Victoria (vv. 466-476) de la Soledad primera:

Si esta noche, o noche tal

flores os sirvió la nieve,

Zodíaco hecho breve

de mucho Sol un portal, adonde un bruto animal, viéndose rayos su pelo, aun con el Toro del cielo se desdeña competir, ¿cuál podréis, Judea, dezir [...]

Señalemos, por fin, a modo de remate de este proceso gongorino de enflorecimiento del mundo por medio de correlaciones semánticas fundadas en la multiplicidad, el esplendor y la belleza, esas coincidencias (a veces proporciones), más escasas pero ingeniosas, de flores por una parte, heridas y panales, espumas y arenas, centellas, aplausos y ruiseñores por otra. El primer caso es el de una agudeza continuada, fundada en las nociones de coste, servicio y pago, observable en los dos sextetos-liras finales de una deliciosa canción de 1608 (De la florida falda), en la que el amante, habiendo tejido / jazmines al cabello desatado de Clori, sufre primero las heridas de un escuadrón volante de abejas, tan numerosas como las flores de la guirnalda: púselas en hüida, / y cada flor me cuesta una herida (vv. 11-12). En la última estrofa, un verso bimembre, brillante cierre del poema, establece una equivalencia entre las flores del servicio amoroso y el galardón esperado de los besos de Clori, convertidos en panales por su dulzura propia y la mención de las abejas:

43 Con una nota justamente entusiasta de Robert Jammes (ed. cit., p. 296), aunque el zodíaco -según reza el verso 12 - no es el buey sino el portal: "Un bruto animal: le bœuf de l'étable, qu'illumine la gloire de l'enfant Jésus, devient le zodiaque d'un soleil, au point qu'il peut dédaigner la splendeur du taureau céleste: cette belle image, éblouissante dans cette composition par ailleurs assez terne, reprend, en le condensant, l'admirable début de la première Solitude. Elle n'est évidemment pas d'essence religieuse". 
Más, Clori, que he tejido

jazmines al cabello desatado,

y más besos te pido

que abejas tuvo el escuadrón armado;

lisonjas son iguales

servir yo en flores, pagar tú en panales.

Señalada la ecuación -lisonjas son iguales-, apunta también a las flores de la retórica amorosa, dignas, como las flores literales, de pagarse en besos de miel. En la Fábula de Polifemo, dos versos (el v. 128 y el v. 502) asocian primero las flores del suelo y las espumas del mar en que vive Palemón y luego los márgenes floridos y las orillas arenosas del río en que se metamorfosea Acis. En el primero, sustenta la expresión literal una doble e implícita proporción 'las flores que pisa Galatea son a la tierra lo que las espumas que pisa Palemón al agua del mar'. Irónicamente comparado con Polifemo y tan feo como él (vv. 125-126: en la gracia igual, si en los desdenes / perdonado algo más que Polifemo), Palemo es (v. 136) delfín que sigue en agua corza en tierra, recalcándose así la validez poética del v. 128: tantas flores pisó [Galatea] como él espumas. Al final del poema, v. 502, transformada la sangre de Acis en líquido aljófar, sus blancos huesos se convierten en corriente plata, en río lamiendo flores y argentando arenas. Más picante es el romance jocoserio, presentado por Góngora, bajo el pseudónimo de Vicario de Trassiera $^{44}$ en una justa poética celebrada en Córdoba, en honor de la beatificación de Teresa de Ávila, en $1614^{45}$. No solo juega con el estatus doble de santa Teresa, medio monja y medio fraile, / soror Ángel, fray Teresa (vv. 15-16), sino que confunde, mezclándolos, dos textos del

44 Robert Jammes lo califica de burlesco en sus Études sur l'ouvre poétique de don Luis de Góngora y Argote, Bordeaux, Institut d'Études ibériques et ibéro-américaines de l'Université de Bordeaux, 1967, p. 231, nota 12. Cf. también en: Luis de Góngora, Romances, ed. de Antonio Carreño, Madrid, Cátedra, 1988, p. 366, la presentación del poema por el editor.

45 "Este romance jocoserio, presentado bajo pseudónimo, fuera de plazo y contraviniendo las normas prosódicas, obtuvo como premio unas medias negras de seda", Antonio Carreira, Antología, p. 512, y nota 24, p. 513, en la que tal vez convenga corregir "III, Reyes" cambiando por "I, Reyes". 
Antiguo Testamento, relativos a la subida de Elías al monte Carmelo, donde humilla a Acab y ofrece un sacrificio a Dios (I, Reyes, 18) y a la de Moisés al monte Horeb, donde ve una zarza que arde sin consumirse y Dios le manda quitarse el calzado de los pies (Éxodo, 3, 5) por ser sagrada la tierra. Si bien llega a ser la santa nueva Elías celante (v. 29) por reformar el Carmelo y fundar conventos, y nueva Moisés por descalza, y por bajar del Monte Carmelo, legisladora, I en tablas más que de piedra / de su antigua institución / la recopilación nueva (vv. 25-28), no es ninguno de los dos personajes bíblicos, señalando Góngora la poética y encomiástica confusión con el adverbio quizá y el indefinido alguna:

Al Carmelo subió, adonde con flores vio y con centellas zarza quizá alguna, pues se descalzó para vella.

Si flores y centellas o centellas como flores florecen en la zarza sagrada, flores eclosionan en aplausos fragrantes para saludar el canto, digno de Orfeo, de Amarilis, la esposa del siempre culto Danteo (v. 33) en el romance de 1622, Para doña María Osorio, mujer de don Antonio Chacón:

el curso enfrenó del río, y a su voz el verde margen, respondiendo en varias flores, aplausos hizo fragrantes.

No falta la palabra lisonja para designar el canto de esta Filomena de las gentes, Amarilis de las aves (vv. 19-20), sirena con plumas de ángel: consiste en un villancico con estribillo en forma de quintilla hexasílabica y dos mudanzas en forma de sextilla combinadas con los últimos tres versos del estribillo. Merecen citarse aquí la letra inicial y la primera sextilla porque reúnen los significantes amor, ruiseñor y flor, manteniéndose la rima consonante a pesar de que afirma la cancioncilla el divorcio definitivo entre la asociación tópica de ruiseñor y flor con la sencilla y sincera expresión del amor: 


\section{¿Quiéreme la Aurora \\ por su ruiseñor?: \\ busque otro mejor, \\ que yo canto ahora \\ a mi dulce amor. \\ Con la alba me envía \\ cuanto jazmin bello \\ trenza en su cabello \\ al nacer del día; \\ poca es mi armonía \\ para tanta flor: \\ busque otro mejor, \\ que yo canto ahora \\ a mi dulce amor.}

Fechada en 1622, la canción cierra un proceso de renovación poética emprendido años atrás. Remontándonos al año 1598, observamos que las estrofas aliradas de la canción Donde las altas ruedas no sin ironía construyen un perfecto lugar ameno en torno al fresno levantado, a cuyo tronco recostado, se queja Coridón:
sobre un peñasco roto,
al tronco recostado
de un fresno levantado,
que escogió entre los árboles del soto
porque su sombra es flores,
su dulce fruto dulces ruiseñores.

La elección del fresno por Coridón le permite al poeta aludir a la valoración del árbol que hace Virgilio en la Égloga séptima: Fraxinus in sylvis pulcherrima, recordando también la ciencia de Plinio que, también citado por Covarrubias, afirmaba que las serpientes aborrecían su sombra: sin serpientes ni áspides, la sombra es flores en el poema, ya porque crecían al pie del árbol, ya, en sentido figurado, porque era la sombra deleitosa. En cuanto al fruto del fresno, si bien el Diccionario de Autoridades lo define "menudo y algun tanto amargo", es dulce en 
el poema, sabroso, no por ser fruto sino dulces ruiseñores, armoniosos o canoros. A este primer poema, sin embargo, no le compete llevar a cabo el cuestionamiento de la juntura flores / ruiseñores. Otra magnífica letrilla, de 1609, destruye el tópico, proponiendo nuevas asociaciones y significantes nuevos:
No son todos ruiseñores
los que cantan entre las flores
sino campanillas de plata
que tocan a la alba;
sino trompeticas de oro
que hacen la salva
a los soles que adoro.

¿A qué flores remite el significante? A ninguna, por cierto, sino a su propia configuración gráfica y acústica, y más aún, al poder imantado que tiene de casar con su pareja consonante, ruiseñores, en el contexto de una naturaleza feliz, deliciosa y poéticamente acuñada. Pero si suena casi automática la rima, no así el pareado, encabezado por la negación $N o$. Si bien no niega ni borra $N o$, la socorrida consonancia sí nos invita a escuchar, en palabras de Robert Jammes, "non le chant des oiseaux, devenu banal, mais des bruits plus humbles et plus riches à la fois: le bourdonnement des abeilles (trompeticas de oro) qui butinent le jasmin, le bruit cristallin du ruisseau (campanitas de plata) qui coule parmi les fleurs", sin hablar del retintín popular o refranesco y escatológico de los primeros dos versos también señalado por Jammes ${ }^{46}$. Como para zapar esa propiedad semiótica de flores de atraer la mecánica consonancia, en el mismo año 1609 y con la misma rima, los tercetos “ ¡Mal haya el que en señores idolatra...!” aislan jocosamente las dos partes del significante rui-señores para crear el neologismo rui-criados:

46 En Luis de Góngora, Letrillas, pp. 10-12. Cita a Torner (Elementos populares en las poesías de Góngora): No son todas palomitas / las que pican en el montón; / no son todas palomitas, / que algunos palomitos son, así como a Correas: No son todas palomas las que están en el montón; de ellas palominos son; o de ellas cagajones son. 
Tenedme, aunque es otoño, ruiseñores, ya que llevar no puedo ruicrïados, que entre pámpanos son lo que entre flores.

Sirvan pues de transición hacia el último apartado de este estudio la crítica y puesta en tela de juicio, por Góngora, de asociaciones y rimas tópicas o automáticas que él sigue usando aunque las denuncia, y examinemos unas imantaciones semióticas en torno a flor.

\subsection{Imantaciones y propiedades semióticas de flor(es)}

Señálense, sin insistir, los paradigmas bien conocidos de rimas consonantes $^{47}$ que, en torno a flor y flores y con esos dos significantes, configuran uno de los motivos de la música rímica en los poemas de Góngora, llamando la atención el que palabras como dolor(es) o rigor(es) se excluyen de las dos series, exclusión que, en cierta medida, conforma su sentido: flor / amor / calor / color / honor / legislador lolor / prometedor / señor / Villaflor por una parte y, por otra: flores / aduladores / alcores / amores / clamores / colores / dores / favores / labradores / mayores / mejores / menores / matadores / murmuradores / olores / pastores / pescadores / retozadores / ruiseñores / señores. Como cualquier listado, esos dos tienen sentido ya que esbozan, en lo que atañe a la posición relevante de final de verso, la cartografía gráfica, sonora y semántica de la "provincia" florida del léxico gongorino. Ciertas asociaciones rímicas hasta llegan a conformar la identidad de un poema entero, por ejemplo las alianzas inauditas prometedor / Flor / señor y señor / Villaflor / honor que remiten directamente a dos décimas de 1624 y 1625: Al conde de Villalba (405, p. 595) y De don Antonio Coloma (412, p. 603). En relación evidente con lo que supone la rima consonante (semejanza o analogía, eco gráfico y sonoro, resonancias semánticas, ingenio y juegos conceptistas) y a modo de conclusión, dos son los puntos que importa ahora examinar: la

47 Cf. el libro de Mónica Güell, La rima en Garcilaso y Góngora, Córdoba, Diputación Provincial, 2008, presentado ante la universidad de Burdeos para su habilitación y que tuve el placer de asesorar. De las 43 rimas en -or, 6 conciernen a la palabra flor, y de las 42 en -ores, 28 conciernen a flores, pp. 344-345 y 346-347. 
atracción paronímica ejercida por flor / flores; la figura de la repetición con la neutralización referencial del significante - pictograma sonoro flor(es).

En un soneto de 1582, "Raya, dorado Sol, orna y colora" (17, p. 23), la música, primero vibrante y "aurificada”, cuyos acordes lanza el primer verso, introduce en el segundo cuarteto un motivo fricativo, Favonio y Flora ${ }^{48}$, que se desenvuelve suntuosamente en medio del primer terceto, cuando aparece Flérida y se abren las flores anunciadas por el nombre de la diosa de la primavera. Nótese que los sonidos fricativos, enmarcados por la previa diseminación y ulterior recolección de palabras idénticas, se dan cada cinco versos, en el quinto y décimo del poema ${ }^{49}$ :

Raya, dorado Sol, orna y colora

del alto monte la lozana cumbre;

sigue con agradable mansedumbre

el rojo paso de la blanca Aurora;

suelta las riendas a Favonio y Flora, y usando, al esparcir tu nueva lumbre, tu generoso oficio y real costumbre, el mar argenta, las campañas dora,

para que desta vega el campo raso borde, saliendo Flérida, de flores; mas si no hubiere de salir acaso,

ni el monte rayes, ornes, ni colores, ni sigas de la Aurora el rojo paso, ni el mar argentes, ni los campos dores.

48 En un romance de 1586, "Levantando blanca espuma" (61, p. 75), si bien no se nombra el viento, las aliteraciones en $f$ y $v$, así como Flora, sugieren el significante Favonio (vv. 29-32): "Favorable, cortés viento, / si eres el galán de Flora, / válgasme en este peligro / por el regalo que gozas".

49 De indispensable consulta es el impresionante libro de María José Vega, El secreto artificio. Maronolatría y tradición pontaniana en la poética del Renacimiento, Madrid, CSIC, 1992. 
En la armonía consonántica, vibrante, del soneto solar, introducen las fricativas un soplo suave, el de Favonio o Céfiro, amante de Flora, y una paronomasia original entre el nombre esdrújulo, Flérida, de la amada -de evidente resonancia garcilasiana ${ }^{50}-\mathrm{y}$ las flores que, al llegar, bordará en el tapiz del campo raso: original, con respecto al modelo renacentista, únicamente por la disposición de las palabras, separadas en los versos de Garcilaso, reunidas en el soneto de Góngora de modo que también se llene de flores, o florezca, el nombre Flérida, motivado por la proximidad de Flora y flores.

Escribe Gracián en el Discurso XXXI, De la agudeza nominal:

El nombre ocasiona los reparos y ponderaciones misteriosas [...]. Es como hidra bocal una dicción; pues a más de su propia y directa significación, si la cortan o la trastruecan, de cada sílaba renace una sutileza ingeniosa, y de cada acento, un concepto ${ }^{51}$.

Ilustra la afirmación de Gracián el romance jocoso de 1590, "Dejad los libros ahora" (42, p. 166-170). Pintándole al señor licenciado Ortiz el retrato de la moza que le hizo sacrificar su gusto al ceguezuelo rüin, empieza tradicionalmente el poeta amante por el cabello. Jugando con los nombres de dos monedas, una de vellón, de cobre, y la otra de oro, logra evocar un color, entre rojizo oscuro y dorado, haciendo que "renazca" la consonancia color / flor en un contexto ajeno al mundo floral:

el cabello es de un color que ni es cuarto ni florín, y la relevada frente ni azabache ni marfil;

50 Garcilaso de la Vega, Poesías castellanas completas, ed. de Elías L. Rivers, Madrid, Castalia, 2a ed., 1972 (1969), Égloga III, Canto amebeo de Tirreno y Alcino, Tirreno, vv. 305-308: "Flérida, para mí dulce y sabrosa / más que la fruta del cercado ajeno, más blanca que la leche y más hermosa / qu’el prado por abril de flores lleno".

51 Baltasar Gracián, Agudeza, II, p. 360. 
Dos son las caras del ingenio gongorino en esos dos versos: además de crear un matiz ambiguo y declarar, desde un principio, que, empezando por el cabello, todo en la bella aspira al dinero (recordemos que la blanca y hermosa mano / [...] es de nieve y de neblí, vv. 37-40), al aislar ese juego sobre el significante, con la puesta de relieve de la rima color / flor-, las dos partes de la hidra verbal florin, flor-orin (la herrumbre que tal vez contribuya a oscurecer el cabello), hace brotar de cada silaba una sutileza ingeniosa. Otro caso: en el bello romance con estribillo, Los montes que el pie se lavan (214, pp. 291-293), la alternancia de palabras en $f$-o $v$-inicial, encabezadas por Flores, si bien crea una armonía fricativa vinculada a la fuga (vocablo oportunamente preferido a 'huida') de la ninfa perseguida por el cazador, también pone de relieve la motivación relativa de los significantes lingüísticos elegidos: el adjetivo fragoso tanto remite al ruido, al fragor, (no actualizados aquí en cuanto significado de la palabra) como a lo áspero, abrupto, anfractuoso del suelo, fragor y aspereza suavizados por las flores y la fricativa bilabial sonora v-:

Flores le valió la fuga

al fragoso, verde suelo,

varias de color, y todas,

hijas de su pie ligero.

A las malezas perdona

mal su fugitivo vuelo; [...]

Y si seguimos con el juego fricativo ¿cómo no oír que las tres fricativas velares sordas (hijas, ligero, fugitivo, enmarcada aquí la -g-por la -f-y la - v-) avivan aún más la huida de la ninfa? En este caso, como en muchos otros y no solo en la poesía de Góngora, la junctura verborum y la consiguiente armonía imitativa son fruto, sin duda alguna, de la excelsa elección del poeta pero, sin incurrir en el pecado cratilista ni pretender que fuga huya o que fragoso lastime pies y tobillos, no es menos obvio que son el lenguaje y su caudal léxico, a la vez convencional y relativamente motivado, los que, a partir de la suavidad fonética de flores combinada con la noción de huida y su significante más "fricativo" fuga, le "dictan" o le proporcionan a un poeta músico, capaz de oír los acordes de la lengua, aquellas palabras 
cuya ensambladura o alternancia logra “dépeindre les choses par l'effet merveilleux des sons" 52 .

Otros ejemplos se pueden citar. En la Soledad primera, los versos 594-599, nombran literalmente la armonía creada en torno a fresco y florespero rechazada por el montañés como si fuera el lugar ameno ardiente desierto de Libia, poblado de serpientes:

al montañés que, ingrato

al fresco, a la armonía y a las flores

del sitio, pisa, ameno,

la fresca hierba cual la arena ardiente

de la Libia, ya cuantas da la fuente

sierpes de aljófar [...]

Más llamativo, más sonoro y esplendoroso, el espectáculo de la novia que sale, seguida de cien villanas, asocia a florida dos resplandecientes palabras:

[...] al tiempo que seguida

la novia sale de villanas ciento

a la verde florida palizada,

cual nueva Fénix en flamantes plumas

matutinos del Sol rayos vestida,

y no descartaré - precisamente por no presentar en su plena autonomía verbal y semántica el significante flor sino la sílaba flor- los versos 345-352 del Panegírico al duque de Lerma (313, p. 489) cuya áspera armonía marcial, definida como estruendo de las armas, también se funda en la repetición de la fricativa inicial $f$-, insertándose la sílaba flor- en el gentilicio del duque Fernando de Medicis:

Entre el concento, pues, nupcial, oyendo

del Arno los silencios, nuestro Sando

52 Mercedes Blanco, "Góngora et la querelle de l'hyperbate", pp. 169-217, y para la cita p. 193, aunque es de imprescindible lectura todo el artículo y las preciosas observaciones sobre el libro de María José Vega. 
las armas solicita, cuyo estruendo

freno fue duro al florentín Fernando;

el Fuentes bravo, aun en la paz tremendo,

vestido acero, bien que acero blando, terror fue a todos, mudo, sin que entonces

diestras fuesen de Júpiter sus bronces.

Citado por José Manuel Martos Carrasco, en su tesis ${ }^{53}$ sobre el Panegírico, explica Pellicer:

No asentía Fernando [de Médicis] a las cosas de España ni al casamiento de Filipo Tercero. Y así entre las mismas fiestas de la boda determinó el duque de Lerma que saliese a campaña don Pedro Enríquez de Acebedo, conde de Fuentes, que tuvo opinión de valeroso capitán, y solo con mostrar las armas sin llegar a las manos puso miedo y acalló a los enemigos de España.

(Pellicer, col. 675)

Dilucidado el sentido de la octava, lo que importa destacar es la presencia del lexema flor-, incluso falto de autonomía, en una estrofa estrepitosa y estructurada por significantes relativos a la música, al ruido o al silencio: concento nupcial de las bodas reales; silencios alevosos y hostiles del Arno, río de Florencia, y metonimia de la ciudad y de la política de los Medicis; estruendo de las armas y de los ejércitos mandados a Italia por el duque de Lerma; terror mudo el capitán Fuentes, ya que vence sin armar ruido y sin necesidad de combatir; bronces: los cañones del conde de Fuentes que, en esa batalla que no tuvo lugar, prescindieron de convertirse en diestras de Júpiter, en manos jupiterinas que fulminan rayo y fuego. En el centro exacto de la octava, los vv. 4 y 5, se lleva a cabo la labor léxica y paronímica marcial, fragorosa, sin embargo algo endulzada, como en la décima de 1610 sobre la toma de Larache, por la presencia del significante flor,

53 El "Panegírico al Duque de Lerma" de Luis de Góngora, Estudio y ed. crítica de José Manuel Martos Carrasco, Tesis doctoral, para optar al título de Doctor en Humanidades, Director-tutor: Dr José María Micó (UPF), Universitat Pompeu Fabra, Barcelona, 1997, vol. III, p. 370. 
primera sílaba del adjetivo florentín, rigurosamente exacto, geográfico e histórico, pero portador de armonía en medio del cuarto verso, uno de los más ruidosos y militares. Mera coincidencia o conciencia aguda de los procedimientos de la elocutio, a partir del sexto verso se ablanda el acero haciéndose persuasivo, enmudece ese terror del enemigo que es el de Fuentes, y si bien siguen manteniéndose los sonidos estrepitosos de la guerra, son negados por la calma jupiterina del último verso. Reserva el Panegírico muchos primores de este tipo: no es de extrañar ya que, siendo el primer texto largo de inspiración épica, política y cortesana de Góngora, también le sirve de banco de pruebas para reelaborar a lo heroico su propia escritura poética. Terminemos ese repaso sonoro con la décima de 1624 Al conde de Villalba, a quien lo habia remitido el conde de Villaflor, para que le diese una empanada de capón que le habia prometido. No necesita comentarse sino haciendo hincapié en el juego con los nombres: la desmembración del apellido Villa /Flor permite un equívoco fundado en flor, sílaba desgajada del apellido, flor botánica y flor trampa, engaño, haciéndole eco la providencial antonomasia Florián. Aunque, con el artículo un y las indicaciones pan y adobo (para que me deis en pan / y en adobo un Florián), puede convocar la referencia 'gallo castrado', ante todo remite al nombre de "un capón cantor de la capilla real, de muy buena voz y de grande boca" 54 , cuya primera sílaba, la misma que la última de Villaflor, permite apreciar cuán ingeniosa, a veces, puede ser la onomástica históricamente documentada, cuando topa con la malicia y destreza de un gran poeta:

Un Conde prometedor que Portugal dió a Castilla

(tal conociera su Villa como conozco su Flor), me remite a vos, Señor, para que me deis en pan y en adobo un Florïán, süavísimo bocón,

54 Cita del ms. Chacón en Luis de Góngora, Obras completas, p. 595. Cf. también los artículos Capón y Florián en el Léxico del marginalismo del Siglo de Oro. 
si le visten al capón

sotana de mazapán.

El grado máximo de la paronomasia y de la homofonía rímica es una figura sencilla pero eficaz de la elocutio: la repetición. Como atestiguan varios de los poemas anteriormente citados y analizados, una de las propiedades semióticas más destacadas del significante flor-que consuena con su propiedad semántica de multiplicarse y diversificarse en elementos análogos- es la de reiterarse idénticamente o por medio de palabras que incluyen la sílaba -flor-, sea en un mismo verso, en el espacio reducido de una estrofa y en posiciones estratégicas de un poema breve, sea diseminada en poemas largos multiplicándose a veces en fragmentos floridos de esos poemas. De los 94 poemas en que se documenta la palabra, casi la tercera parte (un 28\%) presenta dos o más recurrencias del lexema. En el curso de este trabajo, ya hemos comentado las figuras sintácticas de la repetición, epanadiplosis, epíforas o epanástrofes en las que flor tiene un papel relevante. Señalemos, a pesar de su obviedad, que la presencia de un estribillo favorece el enflorecimiento de un poema como por ejemplo: Las flores del romero, / niña Isabel, / hoy son flores azules, / mañana serán miel, cuyos últimos dos versos se repiten al final de las dos estrofas del romancillo (1608, 192, p. 268) o el ya citado: No son todos ruiseñores / los que cantan entre las flores, / sino campanitas de plata / que tocan a la alba, I sino trompeticas de oro, / que hacen la salva / a los soles que adoro, íntegramente repetido tres veces más en el poema. Recordemos también el final del romance, dramatizado y compuesto de varias partes, de la colmeneruela, moza de cántaro que se fuga con su amante, repitiéndose dos veces el estribillo de la conclusión:

Decidle a su madre, Amor,

si la viniere a buscar,

que una abeja le lleva la flor

a otro mejor colmenar;

picar, picar,

que cerquita está el lugar.

El ejemplo más brillante es el de las décimas dedicadas al Marqués de Flores (1621, 370, p. 566), en que la maestría técnica (los últimos cuatro 
versos de cada una de las cinco décimas son los de la cuarteta que abre el poema y dicta la rima del segundo verso de enlace ${ }^{55}$ de cada décima) se alía a una adecuación perfecta entre el nombre del dedicatario (Flores), el tema (la fragilidad de la vida comparada a la de las flores), la identidad del locutor: la flor de la maravilla, los cinco ejemplos elegidos, cinco flores: la efímera maravilla, el clavel, el jazmín, el alhelí y el girasol. Seis veces se repite la celebradísima cuarteta:
Aprended, Flores, en mí
lo que va de ayer a hoy,
que ayer maravilla fui,
y hoy sombra mía aun no soy,

en el texto más florido de la poesía de Góngora, con un total de 12 recurrencias de flor y el notable enflorecimiento de la décima central, dedicada al jazmín y citada anteriormente.

En otros fragmentos, pone paradójicamente énfasis la repetición de un solo y mismo significante en el número y variedad de su referente, por ejemplo en el soneto "La dulce boca que a gustar convida" (1584, 41, p. 48, vv. 6-8): "porque entre un labio y otro colorado / Amor está, de su veneno armado, / cual entre flor y flor sierpe escondida" o, al contrario, introduce un equívoco entre el sentido literal y el metáforico de la palabra, ingeniosamente colocada, a modo de bisagra, entre una fórmula metafórica y otra, tópica, en la que es flor botánica: Moriste, ninfa bella, / en edad floreciente, I que la muerte entre flores / se esconde cual serpiente (1594, En la muerte de doña Luisa de Cardona, 103, p. 161, vv. 1-4), cuando no despliega, duplicando la palabra en alguna que otra epanalepsis, los campos de referencia de la excelencia floral: contra los elementos de una vida, / florida en años, en beldad florida (1620, En la muerte de un caballero mozo, 333, p. 529, vv. 6-7). En un romance morisco remoto, de 1584, sale

55 Esos son los versos de enlace: pues de vosotras ninguna / deja de acabar así, / aprended, Flores, en mí; efímeras del vergel, / yo cárdena, él carmesí, / aprended, Flores, en mí; si el ámbar florece, es ella / la flor que él retiene en sí, / aprended, Flores, en mi; morir maravilla quiero / y no vivir alhelí, / aprended, Flores, en mí; ojos son aduladores / cuantas en él hojas vi, / aprended, Flores, en mí. 
el gallardo Abenzulema a cumplir el destierro / a que lo condena el rey, / o el amor, que es lo más cierto (49, p. 57-59, vv. 25-32):

Servía a una mora, el moro,

por quien el rey anda muerto,

en todo extremo hermosa

y discreta en todo extremo.

Diole unas flores la dama,

que para él flores fueron

y para el celoso Rey

hierbas de mortal veneno;

Nada más deleitosamente conocidos como los personajes, la situación, la estilización y sencillez del retrato y nada tan sutil como el manejo de la repetición, desde la más elemental (mora/morol/muerto) o la más artificiosa (la epanalepsis que coloca en los extremos de dos versos la fórmula en todo extremo), hasta la más sugerente, en forma de rima interna, aplicada al significante flores. Las flores que le da al galán moro la bellísima Balaja (v. 81) sufren una doble metamorfosis, convirtiéndose para el rey celoso en hierbas de mortal veneno y para el amante, colmo paradójico de la metamorfosis, en ellas mismas, pero flores más bellas y preciosas que las primeras, como si, al favor de la distancia que separa el dar del recibir amoroso y de la oposición entre las flores que halagan y enamoran y las hierbas venenosas, la repetición se convirtiera en gradación enfatizante, en hiperbólica valoración de las segundas flores $^{56}$.

En los 1091 versos de la Soledad primera, aparece unas 20 veces la palabra-sílaba flor, lo que podría parecer poco (y sin duda lo es), si no se

56 Parecer algo distinto es el de Jesús Ponce Cárdenas, Cinco estudios polifémicos, p. 98, que, fijándose en la desdicha del joven moro, recalca el valor de flores como trampas: "Como puede inferirse de la lectura del pasaje, el ramillete de flores que la hermosa mora donó como ofrenda cortés a Abenzulema se tornó en motivo de su desdicha, ya que en realidad llegaron a suponer para el héroe tanto meras 'flores' (pues contrastan con las 'hierbas venenosas' que simbolizan para el rey) como una 'trampa' fatal, pues ocasionaron la furia celosa del monarca y el consiguiente destierro". Fijándome en los versos en que se da la duplicación de flores, se me ocurrió más bien la valeur ajoutée de maravilloso favor o muda y florida prueba de amor. 
agruparan las recurrencias de flor en deslumbrantes fragmentos entre los que destaca la introducción del epitalamio de las bodas rústicas, también él florido, como era de esperar, no tanto por la repetición de flor como por los claveles engastados en el cabello, las rosas que engarza la concordia y las mosquetas y azahares que flechan o nievan los cupidillos. Seis versos (755-760) se dedican a la evocación del cortejo nupcial encabezado por los esplendorosos y floridos novios:

El numeroso al fin de labradores

concurso impaciente

los novios saca: él, de años floreciente,

y de caudal más floreciente que ellos;

ella, la misma pompa de las flores,

la esfera misma de los rayos bellos ${ }^{57}$.

Espléndidos son esos versos florales y solares, con las dos recurrencias del adjetivo virgiliano floreciente aplicado a la juventud y a la prosperidad económica del novio, y el fausto de esa pompa de las flores en que se metamorfosea la novia, también esfera radiante del sol, por la correspondencia ya evocada entre las flores y los rayos. Tal vez proporcionen esos versos entusiasmados una clave que permita definir uno de los empleos más logrados del elemento flor en la poesía de Góngora. Explicada literalmente la doble referencia de floreciente (años y caudal), no necesita preocuparse el lector por dilucidar equívocos o juegos bisémicos. Suspendiendo, pues, la búsqueda del sentido, a lo que invita el fragmento es al placer de su música y de su luz. Dulzuras acrecentando a dulzuras, la triple presencia del pictograma sonoro flor y la secuencia fónica de los tres pronombres, puestos de relieve y aislados: ... él... /... ellos / ella ...o magníficamente reunidos y perceptibles en el adjetivo ...bellos, producen el pasmo o la maravilla que uno siente ante el poder sensorial o sensual del significante. Este poder lo comparte la referencia básica, mínima, de las palabras con su configuración gráfica y fono-simbólica. Sin entrar en la peliaguda cuestión del fono-simbolismo ni convocar teorías, yo diría, para concluir, que igual deleite proporcionan los ingeniosos juegos referenciales o semánticos con un significante, como su mera percepción

57 Cito las Soledades por la edición de Robert Jammes, Madrid, Castalia, 1994. 
en cuanto objeto verbal, gráfico y sonoro -intuitiva e inmediatamente relacionado con un significado, cifrado en la forma de su propio sonido o grafismo-.

En cuanto objeto sonoro, y a pesar de la distancia abismal que separa la escritura gongorina de la letra de las óperas de Wagner, un artículo de Thierry Poirot ${ }^{58}$, "La phonation wagnérienne ou le chant des passions dans la Tétralogie", propone un análisis de la oralización de las emociones en el canto wagneriano fundado en el estudio de la fonación de ese canto realizado por un amigo de Wagner, Hans von Wolzogen (18481938), estudio anterior a los trabajos de Humboldt, Saussure, Jakobson, Toussaint, Fonagy, etc. Me han parecido sugerentes -y adaptables a la palabra flor tal como se "oye" en los versos de Góngora- las descripciones que hace Wolzogen de las consonantes, asociando su fonación a ciertas emociones. La fonación de la fricativa labio-dental sorda $f$, es tierna y suave, halagadora, a la vez soplo y suspiro, representativa del deseo y del placer; la de la fricativa labio-dental sonora, $v$, igualmente tierna y suave, ligera, cálida y escurridiza; la de la líquida $l$, fluida, tierna, agradable, suave, luminosa; la vibrante $r / r r$, verdadero "trino fonológico", denota insolencia, movimiento, energía, emoción; y el grupo $f l$ resulta ser una combinación ligera, viva, fluida y suave, deleitosa. Cabe añadir que la -oacentuada (por tratarse de una palabra monosilábica), situada en sílaba trabada y seguida de la $-r$ final, se pronuncia, por esos varios motivos, abierta o "luminosa", como la llaman ciertos lingüistas.

Sin embargo, no faltarían reparos a ese tipo de análisis. Uno de ellos aparece en una cancioncilla popular ${ }^{59}$ : La primer novia que tuve / todas las "efes" tenía, / Franscisca, fresca, fregona, I fea, flaca, floja y fría, en que la $f$, asociada a contenidos peyorativos no tiene las cualidades halagadoras susodichas, cosa que, una vez más, confirma la afirmación saussureana de que significante y significado son, como las dos caras de una hoja de papel, inconcebibles el uno sin el otro. Tampoco faltan testimonios de tratadistas y poetas atentos a la calidad musical de fonemas y palabras,

58 En Revue Française de Musicothérapie, XXXVIII, 1, pp. 29-36, consultable en internet, el 26 de enero 2010, http://revel.unice.fr/rmusicotherapie/index. html?id $=3050$

59 Le agradezco a mi colega y amiga María Aranda -que ha tenido la generosidad de leer este trabajo- haberme señalado esa cancioncilla. 
como felizmente recuerda Jesús Ponce Cárdenas, en la "Introducción” a su edición de la Fábula de Polifemo y Galatea ${ }^{60}$.

Asimismo, el jeroglífico o pictograma flor, tan corriente y conocido, no produce en la mente ninguna imagen de flor ni remite a ninguna flor. Cuando aparece en un poema, solo o repetido, en singular o en plural, aislado o como sílaba de otra palabra (derivada o no), es tan abstracto su significado, tan íntimamente ligado a su forma, que ese significado no es más, al fin y al cabo, que su forma. Solo el contexto, a veces con dificultad, permite atribuirle un sentido y una o más referencias precisas posibles. La percepción visual del vocablo flor, como la de fleur en francés, también produce una emoción estética, una diminuta e instantánea maravilla, sobre todo si se repite el pictograma.

Espero haber sugerido que la presencia, a la vez cuestionable y halagadora, de flor en el lenguaje poético de Góngora, supone dos lecturas simultáneas: la lectura preocupada por el sentido, lectura intelectual, inquisitiva, erudita, ingeniosa por un lado y por otro, la lectura sensorial, musical y visual, rítmica, fono-simbólica y pictográfica, tan deleitosa como la otra y siempre sensible a la feliz y permanente unicidad de un significante capaz de insertarse y repetirse en una variedad notable de contextos referenciales. Sea la última palabra de este recorrido, la de Jean-Luc Puyau ${ }^{61}$ :

Aussi n'est-ce peut-être pas en dépit des répétitions imposées, des symétries, des parallélismes, et de toutes les formes de redondance qu'on y rencontre que le message poétique nous frappe par sa densité sémantique, mais bien grâce à cet apparat complexe d'itérations qui contribue à focaliser la matérialité du signifiant, gare de départ pour une dynamisation des éléments mimétiques qui le constituent.

60 Jesús Ponce Cárdenas, "Las armonías fónicas”, pp. 127-132. Notables son, por ejemplo, los comentarios de Herrera, Torquato Tasso, Bembo, Juan de la Cueva acerca de la gracia, dulzura y belleza de la $l$, considerada no como consonante sino como semivocal.

61 En su espléndida tesis: La Poétique de Jorge Guillén. Étude linguistique des manuscrits de "Cántico", Préface de Marie-France Delport, Madrid, Casa de Velázquez, 2009, pp. 40-41. 